\title{
A simple nozzle-diffuser duct used as a Kuroshio energy harvester
}

\author{
Po-Hung Yeh ${ }^{1}$, Shang-Yu Tsai ${ }^{1}$, Wei-Ren Chen ${ }^{1}$, Hsing-nan Wu ${ }^{1}$, Meng-Chang Hsieh ${ }^{2}$, Bang-Fuh Chen ${ }^{1, *}$ \\ ${ }^{1}$ Department of Marine Environment and Engineering, National Sun Yat-sen University, Taiwan \\ ${ }^{2}$ Institute of Undersea technology, National Sun Yat-sen University, Taiwan \\ *henbf@mail.nsysu.edu.tw
}

\begin{abstract}
In response to the increasing energy demand in Taiwan and the global trend of renewable energy development, Kuroshio energy is a potential energy source. How to extract this invaluable natural resource has then become an intriguing and important question in engineering practices. This study conducted a study for a nozzlediffuser duct (NDD) as the Kuroshio currents energy harvester. The computational fluid dynamics (CFD) software ANSYS Fluent was employed to calculate the drag and added mass coefficients of the duct anchored to the seabed. Those coefficients were further imported into Orcaflex to simulate the motion of the duct under normal and storm wave conditions. Results showed that the duct was stable $25 \mathrm{~m}$ below the sea surface under normal wave condition. When the wave condition changed to storm waves, the duct needed to dive into at least $90 \mathrm{~m}$ below the sea surface to regain its stability and obtain high power take-off (PTO). An optimal design nozzle-diffuser-duct was reported and a PTO peak of $15 \mathrm{~kW}$ was expectable in the Kuroshio currents. Once a suitable offshore platform can be developed with sixty-six NDDs, a Megawatt Kuroshio ocean current power generation system is feasible in the near future.
\end{abstract}

Keywords: Kuroshio currents, Current energy harvester, ANSYS Fluent, OrcaFlex, Nozzle-Diffuser Duct (NDD)

\section{Introduction}

Even though the electricity energy demand in the world keeps increasing in most countries, the primary electricity generation is still from non-renewable fuels like coal, natural gas, nuclear, and petroleum. However, burning fossil fuels is harmful to the environment, and fuel supply is usually limited and subject to price volatility. Nuclear power, a low-carbon power generation method though, also poses sharp threats to human beings and the environment. Disposal of nuclear waste, potential radioactive contamination by accidents and sabotage, and the threat of nuclear proliferation are merely three of many unresolved controversies that prevent using nuclear power to generate electricity for civilian purposes. In contrast, green energies, such as solar, wind, and ocean powers, are indigenous, non-polluting, and inexhaustible. After being developed for decades, the technologies for both the solar and wind power generation are mature. Yet, the development of ocean current power generation is still under headwind.

Taiwan relies on importing most of the energy resources, to ensure long-term sustainability and energy supply security, diversifying energy supply to renewable energy is a national energy strategy for Taiwan. Among the three aforementioned renewable energy technologies, the potential of wind power generation in Taiwan is the highest. The average wind speed of the northeast monsoon usually exceeds $4 \mathrm{~m} / \mathrm{s}$, making many coastal and offshore areas in Taiwan quite abundant in wind energy. As of 2018, the capacity of wind power in Taiwan was 704 MW (Bureau of Energy, 2019). Taiwan government also aims to increase the capacity of offshore wind power to $5.5 \mathrm{GW}$ by 2025, according to the Ministry of Economic Affairs (MOEA). However, the available wind speed to generate power is largely affected by the variation of weather. While most of the available wind speed occurs during the winter time, high energy use usually happened in the summer when the wind speed is relatively low. Due to this seasonal non-uniformity, although the capacity factor of wind power could obtain as high as $70 \%$ in the winter time, only $6 \%$ would achieve in the summer season (Bedard 2006). It has hampered wind power from becoming a reliable energy supply in Taiwan. On the other hand, ocean energy has the advantages to become a good alternative energy source. It includes both the wave power generated by surface waves and tidal power created by the moving water driven by tides. These two kinds of power can be harvested to transformed into electricity, and thus have the potential to provide a substantial 
amount of renewable energy. It is expected to fulfill the gap that the share of renewable energy should reach $20 \%$ by 2025 . Taiwan is an island situated at the west Pacific Ocean, and strong ocean current flows pass Taiwan all the time. Seasonal non-uniformity of weather and shortage of land resources are no more the essential issues to obstacle its development. Thus, whether the technology is able to capture the energy successfully and the power generation system can survive in the violent marine environment have become the most critical and relevant challenges for the island nation to reach its goal.

\subsection{Kuroshio Current}

As shown in Figure 1, the Kuroshio currents is a strong ocean current flowing northerly on the west North Pacific Ocean, comprising the western boundary of the North Pacific Subtropical Gyre (NPSG). It originates from the westward flowing North Equatorial Current (NEC) at the east coast of Luzon, Philippines, flows northerly passing the east coast of Taiwan and Japan, and eventually merges into the eastward flowing North Pacific Current (NPC). Analogous to the Gulf Stream in the Atlantic Ocean, the Kuroshio transports a large amount of heat and warm water from the tropics towards the polar region. Its speed is about $0.5-2.0 \mathrm{~m} / \mathrm{s}$ and the current has a volume transport measured about $20-40 \times 10^{6} \mathrm{~m}^{3} / \mathrm{s}$ which is about 100 times more than the Amazon River (Chen, 2010). Comparing to wind power generation, which needs the wind speed to reach at least $9.0 \mathrm{~m} / \mathrm{s}$ for a well wind farm, ocean current only has to obtain one-tenth the speed to generate the same amount of power because of the density difference between the air and seawater. Besides, the wind turbines are not able to work for twenty-four hours per day since the appropriate wind speed is not always available. Ocean current, such as the Kuroshio current, is stable in flow with little fluctuation regardless of time. An efficient generator converting power of the ocean current may be functioning for more than three hundred days in a year (Chen, 2010). As such, the massive power of the Kuroshio current will constitute a stable power source.

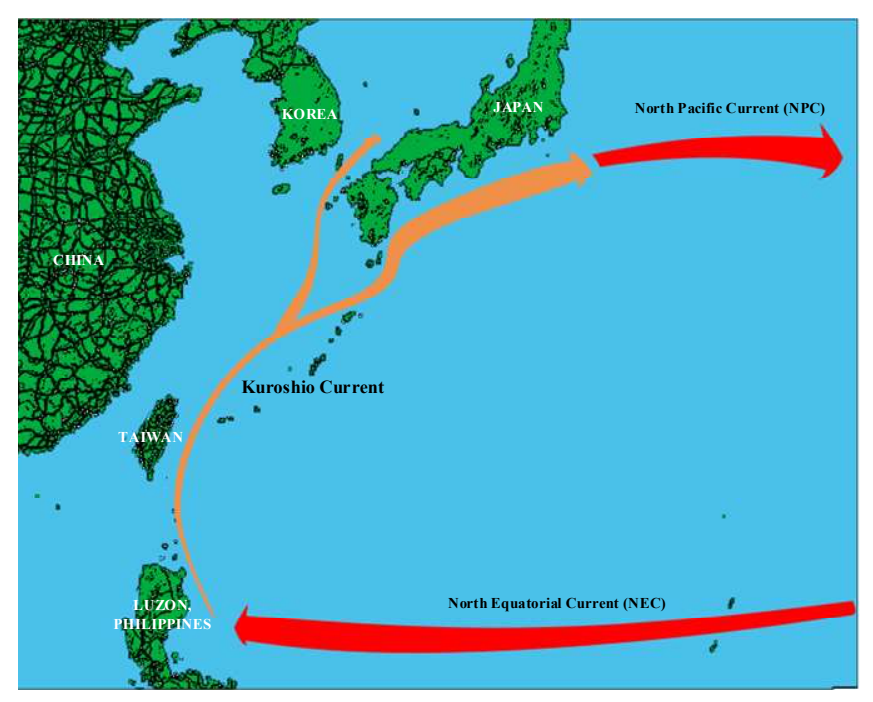

Figure 1 Schematic drawing for the path of Kuroshio current on the west North Pacific Ocean.

\subsection{Development for Ocean Current Energy Harvester}

Three teams from three different universities in Taiwan, National Taiwan University (NTU), National Sun Yat-sen University (NSYSU) and National Taiwan Ocean University (NTOU), had made progresses to conduct preliminary studies on power harvesting from the Kuroshio current. The Floating Kuroshio Turbine (FKT) system (Figure 2) was the collaboration by NTU and NTOU (Lo, 2017). Laboratory flume test demonstrated that a $1 / 25$ model could generate $850 \mathrm{~W}$ of power when the model was towed at speed of 1.45 $\mathrm{m} / \mathrm{s}$ (Wu et al, 2018). Feasibility study for a $1 / 5$ model has been conducted; it is expected the larger model would generate higher power up to $20 \mathrm{~kW}$. The team from NSYSU designed a floating nozzle-diffusor duct (NDD) power generation system (Figure 3a) and deployed successfully in the sea area near the Penghu cross sea bridge in 2013 (Figure 3b). The in-situ test for the power take-off (PTO) of the system reached as high as $5 \mathrm{~kW}$ (Chen et al 2018). A successive new design with circular nozzle-diffusor duct is then expected to increase the PTO three times more than the previous model (Chen and Huang, 2016). Another team from 
NSYSU, cooperating with THL (Tainan Hydraulics Laboratory) and Wanchi Steel Industry Company, developed a $50 \mathrm{~kW}$ Kuroshio ocean current power-energy harvester (Chen et al 2016). During the 60-hour open-water towing test at southeast Taiwan in 2016, an average of $26 \mathrm{~kW}$ power was reported under the current speed of $1.27 \mathrm{~m} / \mathrm{s}$.

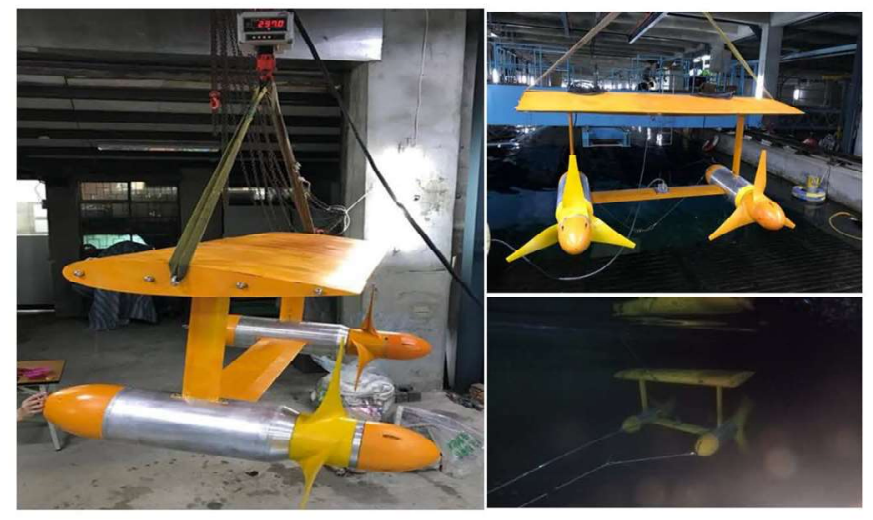

Figure 2 Prototype of Floating Kuroshio Turbine (FKT) [13,16].

(a)

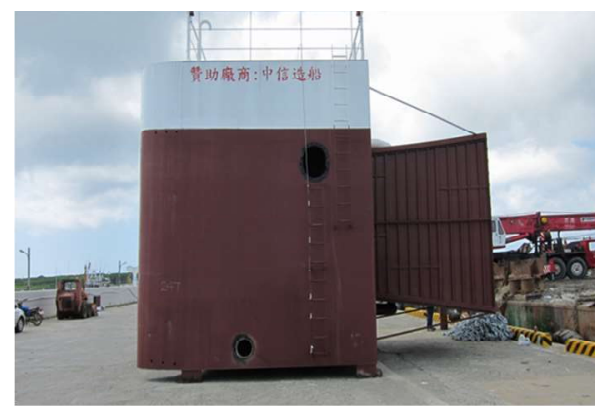

(b)

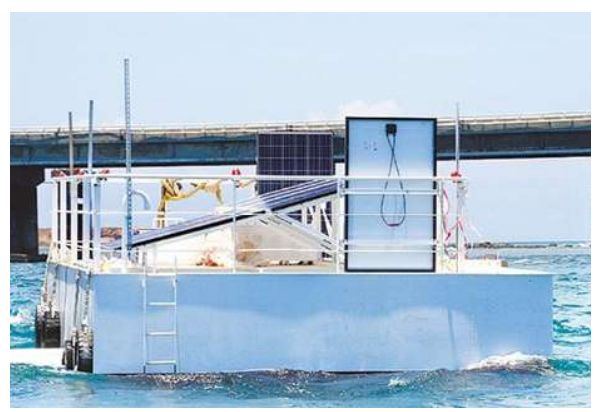

Figure 3 Prototypes of NSYSU designed (a) floating nozzle-diffusor duct (NDD) power generation system and (b) deployed successfully in the sea area near the Penghu cross sea bridge in 2013 (Chen et al, 2018).

Besides the aforementioned developments in Taiwan, Japan's New Energy and Industrial Technology Development Organization (NEDO) together with IHI Corporation and Toshiba Corporation, have been developing a next-generation ocean energy power generation, the so-called underwater floating type ocean current turbine system. The underwater floating "Kairyu" (Figure 4a) is a $100 \mathrm{~kW}$ power generation system with two $50 \mathrm{~kW}$ counter-rotating turbines of 11 -m blades. The system also includes a $20 \mathrm{~m} \times 20 \mathrm{~m} \times 11 \mathrm{~m}$ generator with an onboard transformer. It will be anchored to the seabed and float like a kite carried and driven by the ocean current (NEDO, 2017). Swedish developer Minesto designed the tidal power generating kite "Deep Green" (Figure 4b) anchored to the seabed and "flying" under water (Minesto, 2017). It was designed specifically to work in the marine environment with slow current speed. A demonstrator has been installed off the coast of Northern Ireland and generating electricity for more than two years. In 2018, a commercial scale $(500 \mathrm{~kW})$ Deep Green was commissioned at the site off the coast of North Wales. Brief literature review for the development of ocean current energy harvester can be found in (Chen et al, 2018). 
(a)

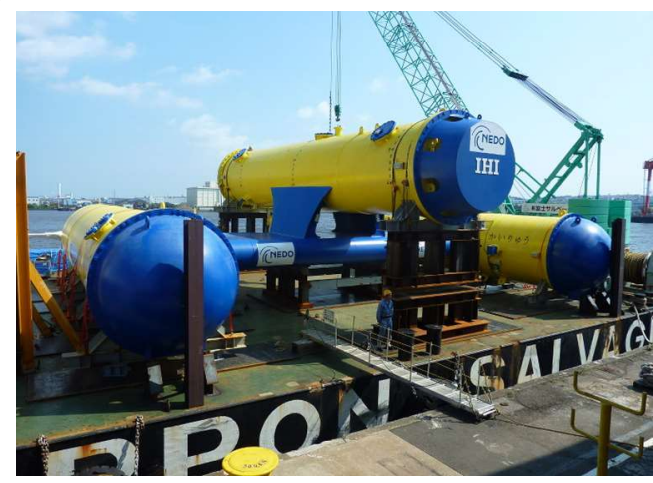

(b)

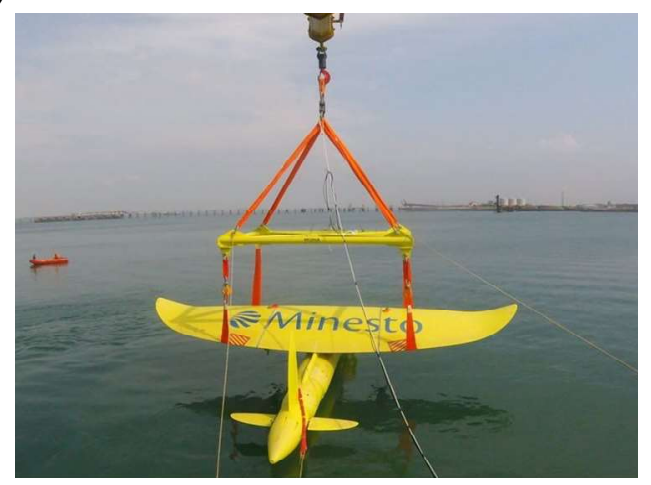

Figure 4 Prototypes of (a) Kairyu of NEDO (NEDO, 2017) and (b) Deep Green of Minesto (Minesto, 2017 ).

The objective of this study was attempted to carry out a feasibility study for the employment of an energy harvester (nozzle-diffusor duct, NDD) (Chen and Huang, 2016, Huang, 2016) in the marine environment of Kuroshio currents. Utilizing ANSYS Fluent, an acceleration method was developed to estimate the drag and add mass coefficients for the $6 \mathrm{DoF}$ motions of the NDD. These coefficients were further used in OrcaFlex to calculate the hydrodynamic forces exerted on a single duct anchored to the seabed. Dynamic simulations under normal and storm wave conditions were then performed to investigate corresponding responses of the system. Adequate submerged depth of the duct to avoid large storm waves and have high power take-off at the same time was discussed. Finally, suggestion for a spar system to carry plural ducts and some concluding remarks drawn from this study were addressed.

\section{Numerical method}

Commercial CFD code ANSYS Fluent was used to conduct numerical simulations. The flow was assumed incompressible with constant density and molecular viscosity. We adopted Reynolds-Average Navier-Stoke Equation Models (RANS) and Standard k- $\varepsilon$ model to solve the flow passing marine turbines. The detail description of the model is as follow:

The RANS momentum equations can be written as

$\rho\left(\frac{\partial \bar{u}_{i}}{\partial t}+u_{k} \frac{\partial \bar{u}_{i}}{\partial x_{k}}\right)=-\frac{\partial \bar{p}}{\partial x_{i}}+\frac{\partial}{\partial x_{j}}\left(\mu \frac{\partial \bar{u}_{i}}{\partial x_{j}}\right)+\frac{\partial R_{i j}}{\partial x_{j}}$

Where $\bar{p}$ is mean pressure, $\bar{u}_{i}$ and $\bar{u}_{j}$ are fluctuation velocities along the $x_{\mathrm{i}}$ and $x_{\mathrm{j}}$ directions respectively; and $\rho$ and $\mu$ are fluid density and dynamic viscosity respectively. $\frac{\partial R_{i j}}{\partial x_{j}}$ represents the perturbation velocity. $R_{i j}=-\rho \overline{u_{i}^{\prime} u_{j}^{\prime}}$ is Reynold shear stress and the Eddy-viscosity model was used ant it can be written as

$R_{i j}=-\rho \overline{u_{i}^{\prime} u_{j}^{\prime}}=\mu_{t}\left(\frac{\partial \bar{u}_{i}}{\partial x_{j}}+\frac{\partial \bar{u}_{j}}{\partial x_{i}}\right)-\frac{2}{3} \mu_{t} \frac{\partial \bar{u}_{k}}{\partial x_{k}} \delta_{i j}-\frac{2}{3} \rho k \delta_{i j}$

Researchers usually used three turbulence models to investigate the optimal turbine blades, and they are "Realizable k- $\varepsilon$ two layer", "standard k- $\varepsilon$ " and "k- $\omega$ SST" and found the results are about the same. The "standard k- $\varepsilon$ " was, therefore, chosen for this study. We then have 
$\mu_{t}=f\left(\frac{\rho k^{2}}{\varepsilon}\right)$ where $k$ and $\varepsilon$ are the turbulent kinetic energy and turbulent kinetic energy dissipation rate and can be defined as $k \equiv \overline{u_{i}^{\prime} u_{i}^{\prime}} / 2$ and $\varepsilon \equiv v \overline{\partial u_{i}^{\prime} / \partial x_{j}\left(\partial u_{i}^{\prime} / \partial x_{j}+\partial u_{j}^{\prime} / \partial x_{i}\right)}$

Turbulent energy equation of the standard $k-\varepsilon$ model equations:

$\frac{D}{D t}(\rho \varepsilon)=\frac{\partial}{\partial x_{j}}\left[\left(\mu+\frac{\mu_{t}}{\sigma_{\varepsilon}}\right) \frac{\partial \varepsilon}{\partial x_{j}}\right]+C_{\varepsilon_{1}} \frac{\varepsilon}{k} G_{k}-\rho C_{\varepsilon_{2}} \frac{\varepsilon^{2}}{k}$

where $G_{\mathrm{k}}$ can be defined as $G_{k}=\rho v_{t} \frac{\partial \bar{u}_{i}}{\partial x_{j}}\left(\frac{\partial \bar{u}_{i}}{\partial x_{j}}+\frac{\partial \bar{u}_{j}}{\partial x_{i}}\right)$.

The values of these constants $C_{\mu}, C_{\varepsilon 1}, C_{\varepsilon 2}$ and $\sigma_{\mathrm{k}}$, are empirically given as $C_{\mu}=0.09, C_{\varepsilon 1}=1.44, C_{\varepsilon 2}=$ 1.92 and $\sigma_{\mathrm{k}}=1.0$. To discretize the governing equations and boundary conditions, the method of Quadratic Upwind Interpolation of Convective Kinematics (QUICK) was used. The velocity and pressure fields were then solved by PISO algorithm. In addition, second-order upwind scheme was employed to obtain more accurate results. For the object geometries and computational domain, AutoCAD and Solidworks were both used; the results were first stored in *.sat and *.iges files and then processed to establish computational meshes by using the Gambit code.

\section{1 domain and convergence tests}

In this study, a nozzle-diffusor duct (NDD) designed by Huang (2016) was used as the device to capture ocean current energy.

(a)

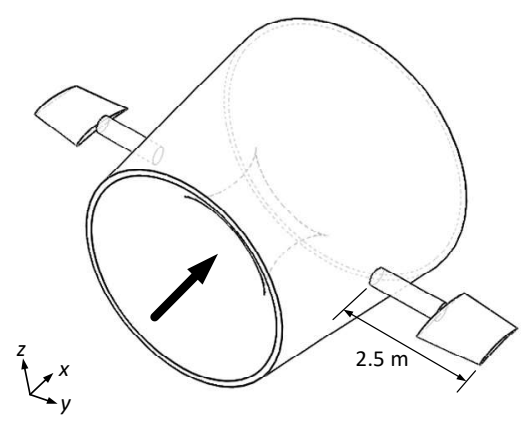

(b)

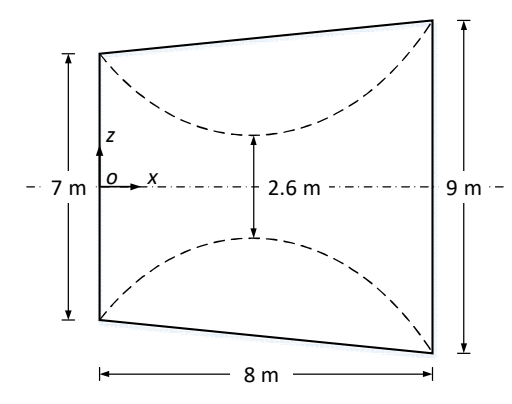

Fig. 5 (a) 3D diagram and (b) plan view of the duct used in the simulations.

Figure 5 shows the 3D diagram and plan view of the NDD used in the simulations. To avoid large mesh deformation near the NDD surface, the smaller grid size surrounding the duct was used. Different initial mesh size, mesh size growth rate, mesh number near the duct and turbine, and total mesh number for computation convergence were tested. Figure 6 shows the convergence tests including domain size test and mesh number test. It was found that by using initial mesh size $=0.05 \mathrm{~m}$, mesh size growth rate $=1.5$, and total mesh number $=1.21$ million, the numerical simulations were able to obtain convergence and provide fair degree of accuracy. 
(a)

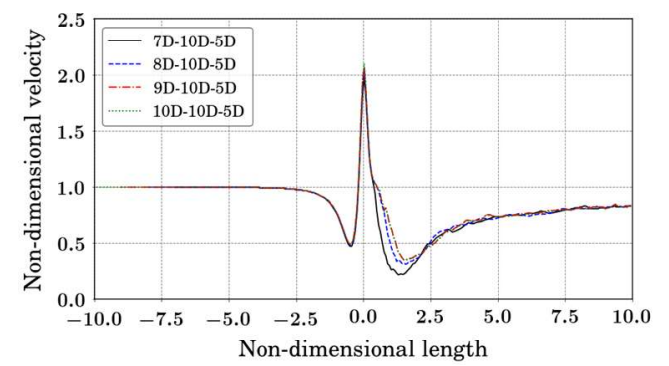

(c)

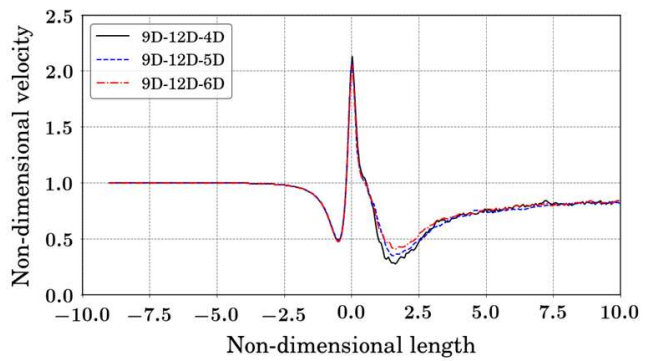

(e)

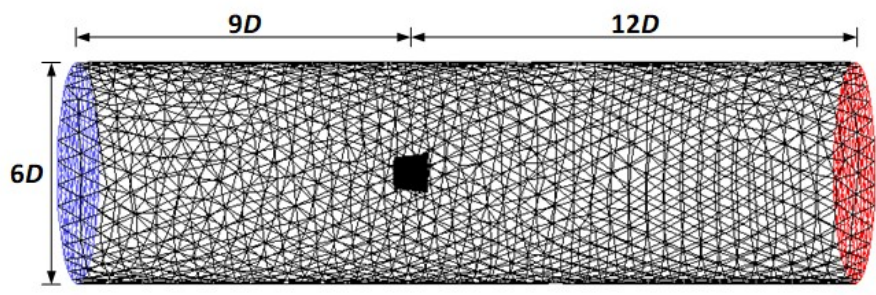

(b)

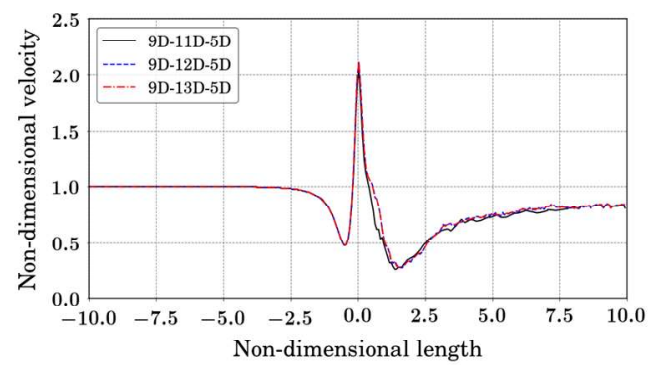

(d)

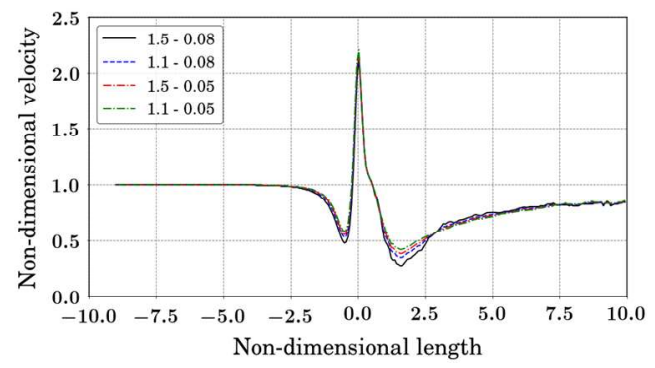

(f)

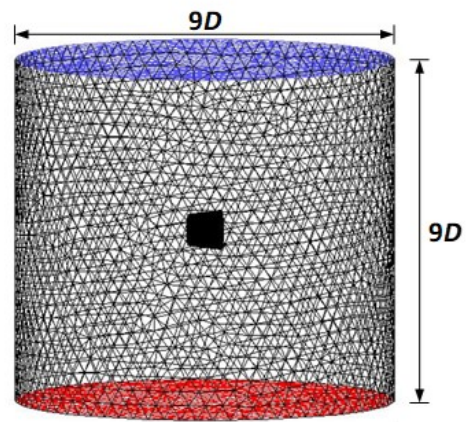

Fig. 6 Comparisons of simulated inline velocity of different domain lengths and mesh numbers: (a) upstrem length $\left(L_{u}\right)$, (b) downstrem length $\left(L_{d}\right)$, (c) side length $\left(L_{s}\right)$, and (d) mesh size and growth rate; The computational domains for (e) translational and (f) rotational motions. $D$ is the nozzle inlet diameter;

\subsection{The use of moving reference frame scheme}

To simulate the flow field when the duct moves with a constant linear acceleration or rotates with a constant angular acceleration, the built-in dynamic mesh model of ANSYS Fluent was used to model flows where the shape of the domain is changing with time due to the movement/rotation of the duct. Fluent Dynamic Mesh Module (this powerful tool is embedded into Fluent). It is a tool that allows the motion of parts (or subparts) relative to static ones, which therefore makes the fluid volume changing in time frame. Profile codes of the linear and angular acceleration were employed to the domain boundaries. Updated mesh was handled automatically by ANSYS Fluent at each time step based on the new positions of the boundaries. Furthermore, in order to avoid the mesh near the object surface deforming too much, the small fluid domain outside the object will moving at the same acceleration it.

When rotary machinery simulation is conducted, the technique of moving reference frame or sliding mesh is mostly considered. In these two techniques, since the method of moving reference frame can facilitate the calculation process and saves computational time, the scheme of moving reference frame is more 
prevailing. Hence a vast majority of previous studies have conducted research based on this method. The following literature is only to name just a few (Zadravec et al, 2007, Tabor et al, 1996, Monteiro et al, 2012 and Corson et al, 2012). Besides, by use of this method, ideal accuracy can be obtained too (Tabor et al, 1996).

Moving reference frame uses relative velocity formulation incorporating Coriolis and centripetal acceleration. Governing equations of conservation of mass and conservation of momentum are listed as follows:

$$
\begin{aligned}
& \frac{\partial \rho}{\partial t}+\nabla \cdot \rho \vec{v}_{r}=0 \ldots \ldots \ldots \ldots \ldots . . . . . . . .(4) \\
& \frac{\partial\left(\rho \vec{v}_{r}\right)}{\partial t}+\nabla \cdot\left(\rho \vec{v}_{r} \vec{v}_{r}\right)+\rho\left(2 \vec{\omega} \times \vec{v}_{r}+\vec{\omega} \times \vec{\omega} \times \vec{r}\right)=-\nabla p+\nabla \cdot \tau_{r}+\vec{F} \ldots \ldots \ldots \ldots \ldots . . . \ldots q .
\end{aligned}
$$

where $\vec{v}_{r}$ is the relative velocity, $\tau_{r}$ is the shear stress tensor. $\rho, \omega, \mathrm{p}$ stands for fluid density, rotational velocity and pressure, respectively. $\vec{F}$ is the external applied force.

As the Reynolds number has already exceeds thousands, the effect of turbulence should be considered in present study. Amongst various turbulent models, some studies adopt k- $\omega$ SST; others adopt standard k- $\varepsilon$ or its related derivative models (Wu et al, 2018, Tabor et al, 1996, Wu et al 2012 and Irungu et al 2019); still others use Spalart-Allmaras (Corson et al 2012, Irungu et al 2019). Considering the robustness of accuracy and rapid prediction like previous studies, we follow suit to employ k- $\varepsilon$ realizable turbulent model, listed in Eq. (3).

\subsection{Mesh around Duct and corresponding $\mathrm{y}^{+}$}

When it comes to difference turbulent models imposed on the simulation cases to carry out numerical calculation, the first layer mesh height should go with their corresponding $y^{+}$. Namely, given different individual model or wall function, $\mathrm{y}^{+}$should be obtained. Studies has suggested that $\mathrm{y}+=30 \sim 300$ when standard $\mathrm{k}-\varepsilon$ is used. And when $\mathrm{k}-\omega \mathrm{SST}$ is used, $\mathrm{y}+$ should equal 1 or so. To this end, the mesh generated on the surface of the turbine is to be more densified, and can be more coarsened away from the turbine, shown in Fig. 7 (a) and (b).

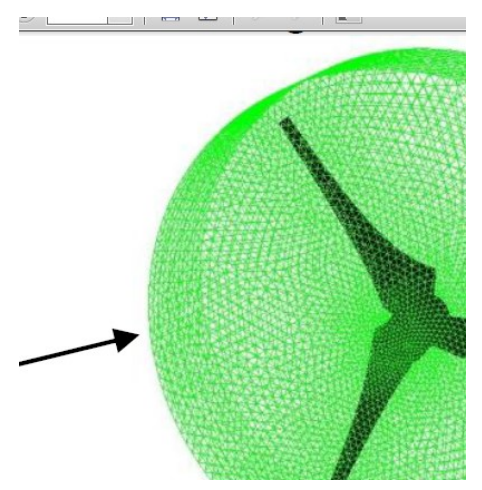

(a)
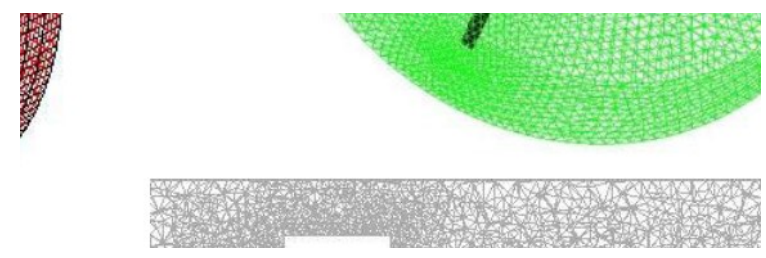

(b) 


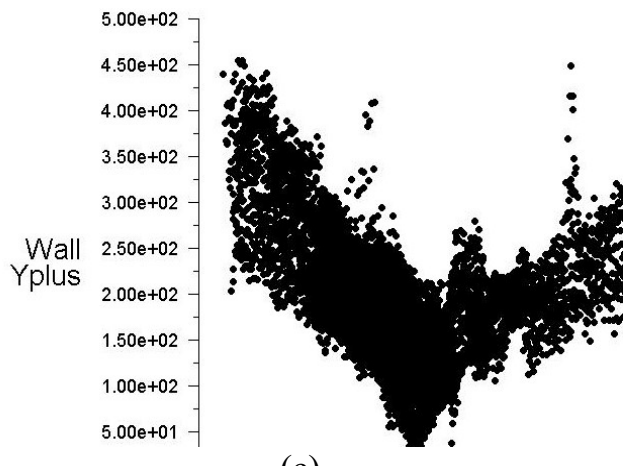

(c)

Fig. 7 (a) mesh generated around the turbine (b) a close-up of the mesh from the turbine wall to outer space; (c) $\mathrm{y}+$ value on the surface of the turbine

Now that $\mathrm{k}-\varepsilon$ model is adopted in present study, it is suggested that the observed $\mathrm{y}+$ should fall within the range between 30 and 300. In present study, $y+$ of the first layer mesh is observed to be around 50 450, as displayed in the Figure 7(c), In this figure, the horizontal axis stands for non-dimensional axial direction of the blade and the vertical axis shows the $y+$ value on the surface mesh points of the blade. Taking the average, we obtain $\mathrm{y}^{+}=195$, which is basically in line with what is suggested by the literature.

\subsection{Drag and added mass coefficients}

Before building a 6D lumped buoy model in OrcaFlex, the added mass coefficient $\left(C_{a}\right)$ and drag coefficient $\left(C_{d}\right)$ are needed to be determined. These two coefficients for all six degrees of freedom (DOF) were calculated by using ANSYS Fluent. Based on small body hypothesis, an object whose characteristic length scale $l_{c}$ is small compared to the incident wavelength $L$ (i.e., $l_{c} / L<<1$ ), the motion of the object has no sensible effect on the incident wave field. The wave-induced hydrodynamic forces on the submerged object can be approximated as the sum of drag force $F_{D}$ and inertia force $F_{I}$

$$
F(t)=F_{D}+F_{I}
$$

where the drag force $F_{D}$ and inertia force $F_{I}$ are the results of shear force and hydrodynamic pressure force acting on the object, respectively. The drag force $F_{D}$ is usually formulated by

$$
F_{D}(t)=C_{d} \frac{1}{2} \rho A v_{r}(t)\left|v_{r}(t)\right|
$$

where $\rho$ is the fluid density, $A$ is the projected area of the object perpendicular to the flow direction, $v_{r}(t)=v(t)$ $-u(t)$ is the relative velocity between the flow instantaneous velocity $v(t)$ and object moving velocity $u(t)$, and $C_{d}$ is the corresponding drag coefficient. On the other hand, the inertia force $F_{I}$ can be divided into the components of Froude-Krylov force and added mass effect,

$$
F_{I}(t)=\rho V \frac{d v(t)}{d t}+C_{a} \rho V \frac{d v_{r}(t)}{d t}
$$

where $V$ is the volume of the object, and $C_{a}$ is the added mass coefficient. Substituting Eqs. (7) and (8) into Eq. (6), the unsteady external force acting on a submerged object is expressed as

$$
\begin{aligned}
F(t) & =C_{d} \frac{1}{2} \rho A[v(t)-u(t)]|v(t)-u(t)|+\rho V \frac{d v(t)}{d t}+C_{a} \rho V \frac{d v_{r}(t)}{d t} \\
& =\frac{1}{2} C_{d} \rho A[v(t)-u(t)]|v(t)-u(t)|+\left(1+C_{a}\right) \rho V \frac{d v(t)}{d t}-C_{a} \rho V \frac{d u(t)}{d t}
\end{aligned}
$$

If the object accelerates from rest within tranquil ambient water, the external force in the above equation reduces to

$$
F(t)=-\frac{1}{2} C_{d} \rho A[u(t)]^{2}-C_{a} \rho V \frac{d u(t)}{d t}
$$


Within a short instant of time $t$, the velocity $u(t)$ of the object is approximated as $u(t)=a t$. Eq. (10) then can be expressed as

$$
\begin{aligned}
F(t) & =-\frac{1}{2} C_{d} \rho A[u(t)]^{2}-C_{a} \rho V \frac{d u(t)}{d t} \\
& =-\frac{1}{2} C_{d} \rho A a^{2} t^{2}-C_{a} \rho V a \\
& =C_{1} t^{2}+C_{2}
\end{aligned}
$$

Eq. (11) indicates that the external force to an object shows a parabolic function against time The magnitudes of the two constants, $C_{1}$ and $C_{2}$, can be obtained by curve-fitting the values of $F(t)$ within a short time after the inception motion of the object. The drag and added mass coefficients, $C_{d}$ and $C_{a}$, are computed by

$$
\begin{aligned}
& C_{d}=-2 C_{1} / \rho A a^{2} \\
& C_{a}=-C_{2} / \rho V a
\end{aligned}
$$

Similar to the above derivation, the equations for rotational motion are to replace the flow acceleration $a$ and projected area $A$ in equation (10) with angular acceleration $\alpha$ and drag-moment area $A_{M}$ (detailed discussion for the drag moment area $A_{M}$ can be found in Tsai, 2018),

$$
\begin{aligned}
M(t) & =-\frac{1}{2} C_{d r} \rho A_{M} \alpha^{2} t^{2}-C_{a r} I \alpha \\
& =C_{3} t^{2}+C_{4}
\end{aligned}
$$

where $I$ is the moment of inertia of the submerged object, and the drag and added mass coefficients for rotational motion are denoted as $C_{d r}$ and $C_{a r}$. The values of these two coefficients again can be computed by the curve-fitting constants $C_{3}$ and $C_{4}$,

$$
\begin{aligned}
& C_{d r}=-2 C_{3} / \rho A_{M} \alpha^{2} \\
& C_{a r}=-C_{4} / I \alpha
\end{aligned}
$$

Figure 8 shows the external force $F(t)$ received by the duct under the translational motion of six degree of freedom $(6 \mathrm{DoF})$. The duct was assumed initially at rest surrounding by tranquil ambient water. A constant acceleration $a=3 \mathrm{~m} / \mathrm{s}^{2}$ was assigned to the duct in each of the three directions. The results revealed that the variation of $F(t)$ did show a parabolic trend within a short time interval $(=1 \mathrm{~s})$. After being fitted by a parabolic function of time ( $t$ ) as derived in Eq. (11), values of the drag and added mass coefficients, $C_{d}$ and $C_{a}$, of the three translational motions were calculated from the coefficients of the regression equation as expressed in Eqs. (12)-(13). Similar procedures were followed as to estimate the three pairs of drag and added mass coefficients, $C_{d r}$ and $C_{a r}$, of the three rotational motions, roll, pitch and yaw. An angular velocity $\alpha=0.2 \mathrm{rad} / \mathrm{s}^{2}$ was again assigned to the duct to rotate with respect to each axis of the coordinate system to get the drag moment of the duct. As shown in Figure 9, the external moment $M(t)$ received by the duct within the first one second can be represented by Eq. (14). Values of $C_{d r}$ and $C_{a r}$ of the three rotational motions were then calculated by the coefficients in Eqs. (15)-(16). All the estimated coefficients are listed in Tables 1-2. 
(a) $\left(\times 10^{6}\right)$

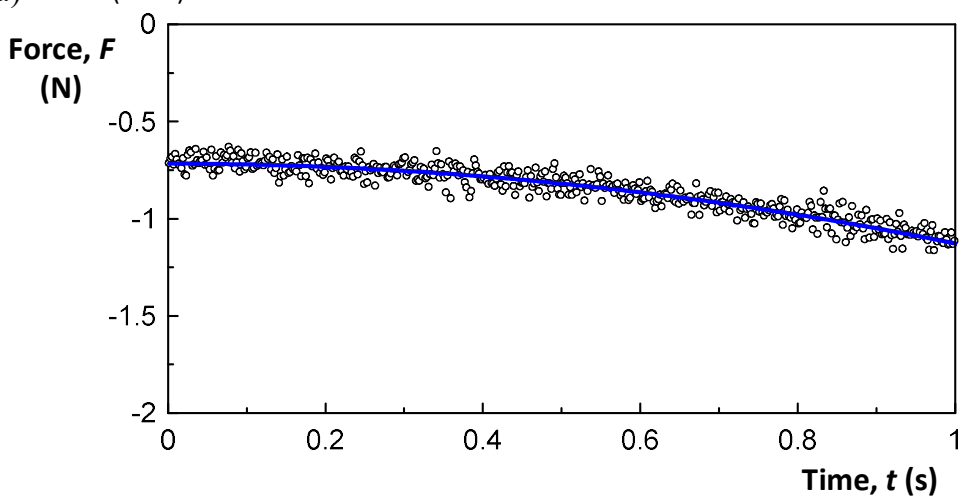

(b) $\quad\left(\times 10^{6}\right)$

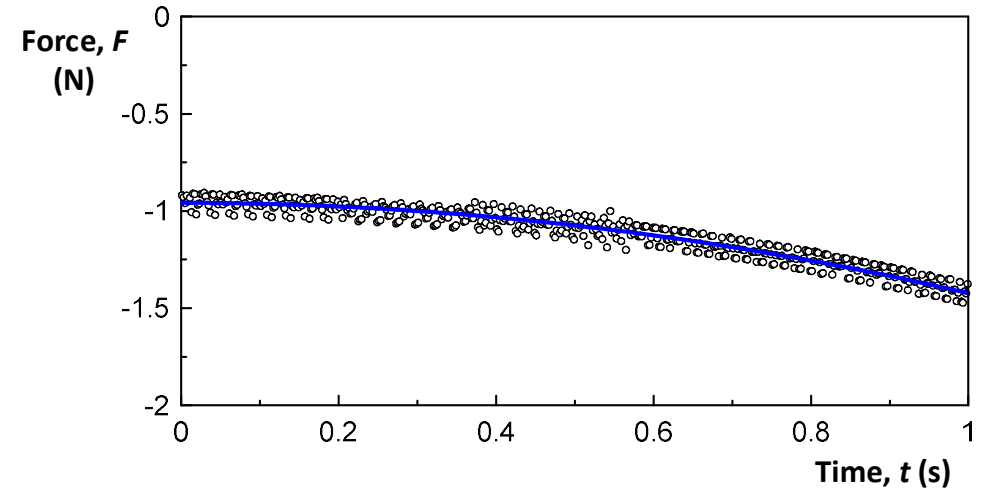

(c) $\left(\times 10^{6}\right)$

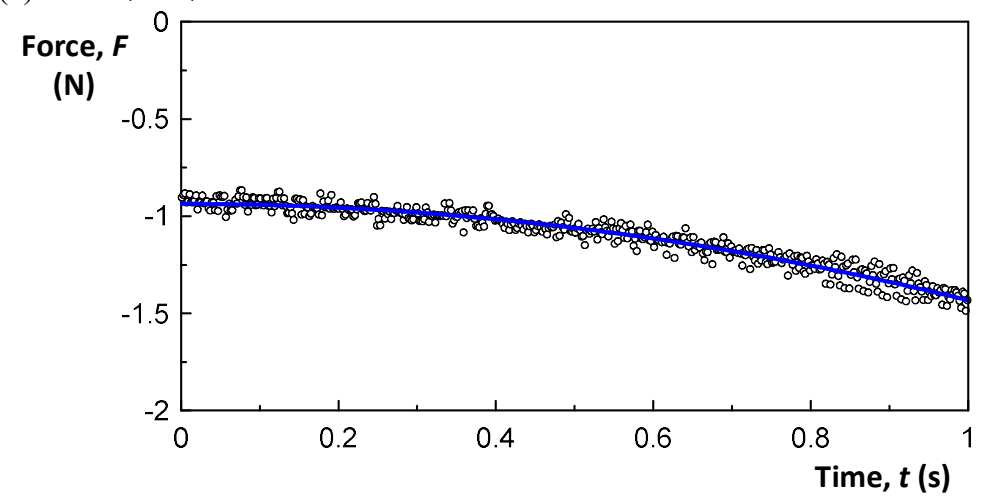

Figure 8. External force received by the duct under the translational motion of six degree of freedom (6DoF).

(a) Surge; (b) Sway; (c) Heave. $\circ$, simulation values; - , Eq. (5) 

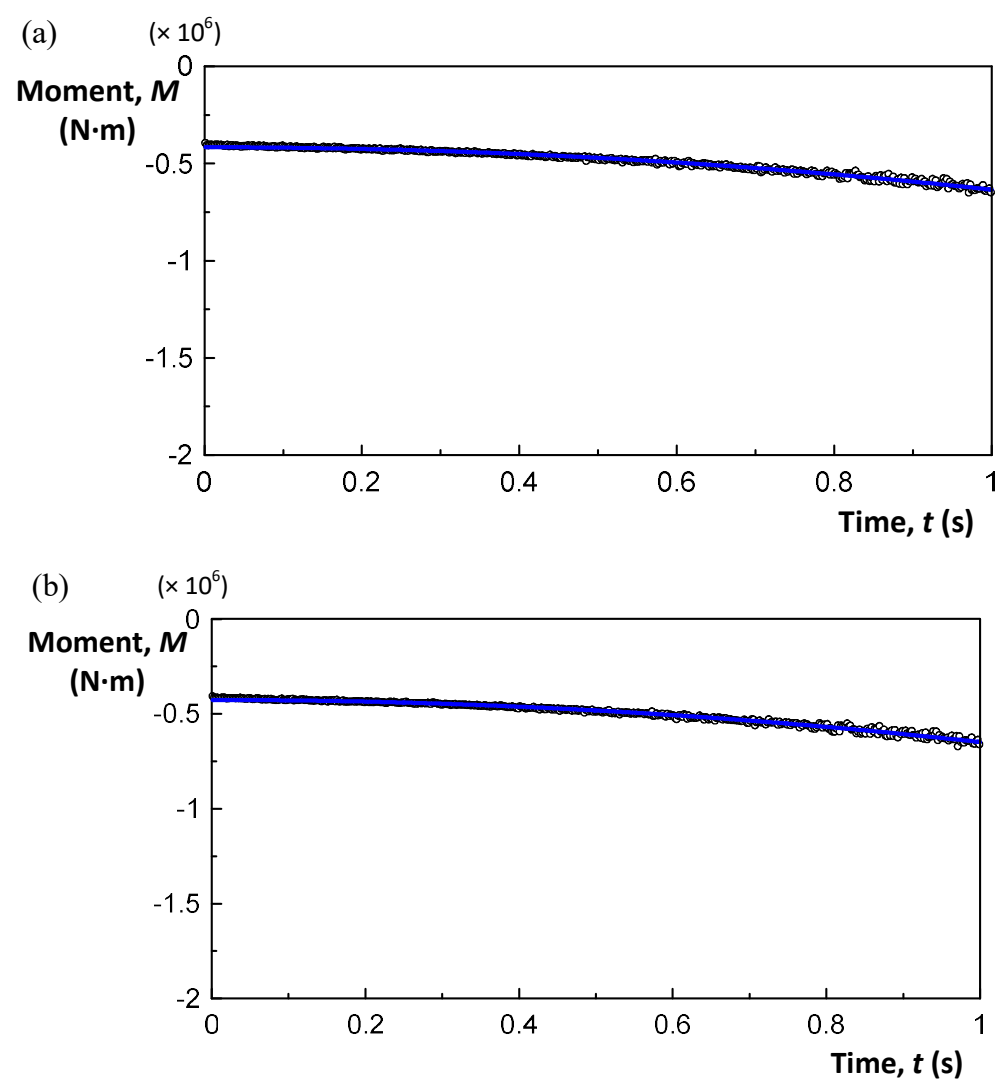

(c) $\quad\left(\times 10^{6}\right)$

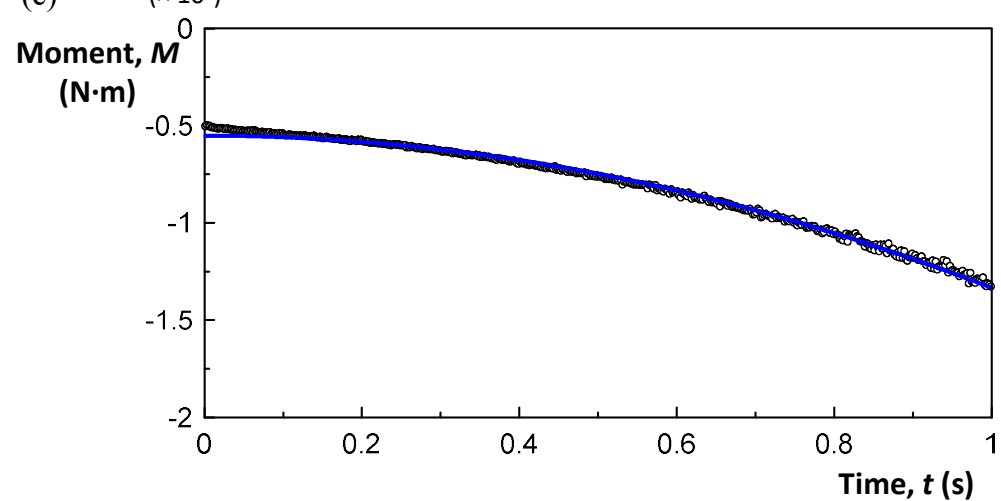

Figure 9. External moment received by the duct under the rotational motion of six degree of freedom (6DoF).

(a) Roll; (b) Pitch; (c) Yaw. o, simulation values; -, Eq. (8)

Table 1. $C_{d}$ for the six degrees of freedom $(6 \mathrm{DoF})$

\begin{tabular}{lcccccc}
\hline & Surge & Sway & Heave & Pitch & Yaw & Roll \\
\hline Drag force $(\mathrm{N})$ & 406497 & 291639 & 457572 & & & \\
Projected area $\left(\mathrm{m}^{2}\right)$ & 67.28 & 67.20 & 78.96 & & & \\
Drag moment $(\mathrm{N}-\mathrm{m})$ & & & & 223137 & 227444 & 374457 \\
Drag moment area $\left(\mathrm{m}^{5}\right)$ & & & & 2153 & 2572 & 7770 \\
$C_{d} / C_{d r}$ & 1.31 & 0.94 & 1.26 & 5.06 & 4.31 & 2.35 \\
\hline
\end{tabular}


Table 2. $C_{a}$ for the six degrees of freedom $(6 \mathrm{DoF})$

\begin{tabular}{ccccccc}
\hline & \multicolumn{3}{c}{ Added mass $(\mathrm{kg})$} & & \multicolumn{3}{c}{ Added moment of inertia $\left(\mathrm{kg} \cdot \mathrm{m}^{2}\right)$} \\
\cline { 3 - 7 } & Surge & Sway & Heave & Pitch & Yaw & Roll \\
\hline Value & 235442 & 291820 & 310403 & 220548 & 217155 & 98398 \\
$C_{a} / C_{a r}$ & 0.69 & 0.86 & 0.91 & 0.65 & 0.64 & 0.29 \\
\hline
\end{tabular}

*The mass of the displaced water is $339305 \mathrm{~kg}$

\subsubsection{Validation of the added mass coefficient of the duct.}

Since experimental data are rare, the accuracy of the added mass coefficient $C_{a}$ by using ANASYS Fluent can be compared to the analytical solution of a smooth sphere. Around a smooth sphere with diameter $D=1 \mathrm{~m}$, the pressure $p$ and velocity potential $\Phi$ around the sphere are

$$
p=-\rho\left[\frac{\partial \phi}{\partial t}+\frac{1}{2}|\nabla \phi|^{2}\right] \text { and } \phi=U \cos \theta \frac{R^{3}}{2 r^{2}}
$$

where $U$ and $R$ are the flow free stream velocity and the radius of the sphere. As a result, the hydrodynamic force acting on the sphere in the direction of the flow $F_{x}$ is

$$
F_{x}=\int_{0}^{\pi}-\rho\left[\frac{\partial \phi}{\partial t}+\frac{1}{2}|\nabla \phi|^{2}\right] \cos \theta 2 \pi R^{2} \sin \theta d \theta=-\frac{2}{3} \rho \pi R^{3} \frac{d U}{d t}
$$

The added mass $m_{a}$ and its coefficient $C_{a}\left(=m_{a} / m\right)$ for this sphere are then defined as

$$
m_{a}=\frac{2}{3} \rho \pi R^{3} \text { and } C_{a}=\frac{m_{a}}{m}=\frac{2}{3} \rho \pi R^{3} / \rho \frac{4}{3} \pi R^{3}=0.5 \text { (analytical value). }
$$

Assigning different accelerations $\left(1,3\right.$, and $\left.5 \mathrm{~m} / \mathrm{s}^{2}\right)$ to a sphere initially resting in tranquil water, the external force $F(t)$ computed by using ANASYS Fluent within the first $1 \mathrm{~s}$ interval is shown in Figure 10. Using leastsquare method to best-fit the simulation data, regression equation of parabolic function $F(t)=C_{1} t^{2}+C_{2}$ can be obtained. The coefficient $C_{2}$ of the regression equation at $t=0$ is close to 0.5 as the analytical value of $C_{a}$. that validate the accuracy of the propose method to calculate the added mass coefficient of the duct.

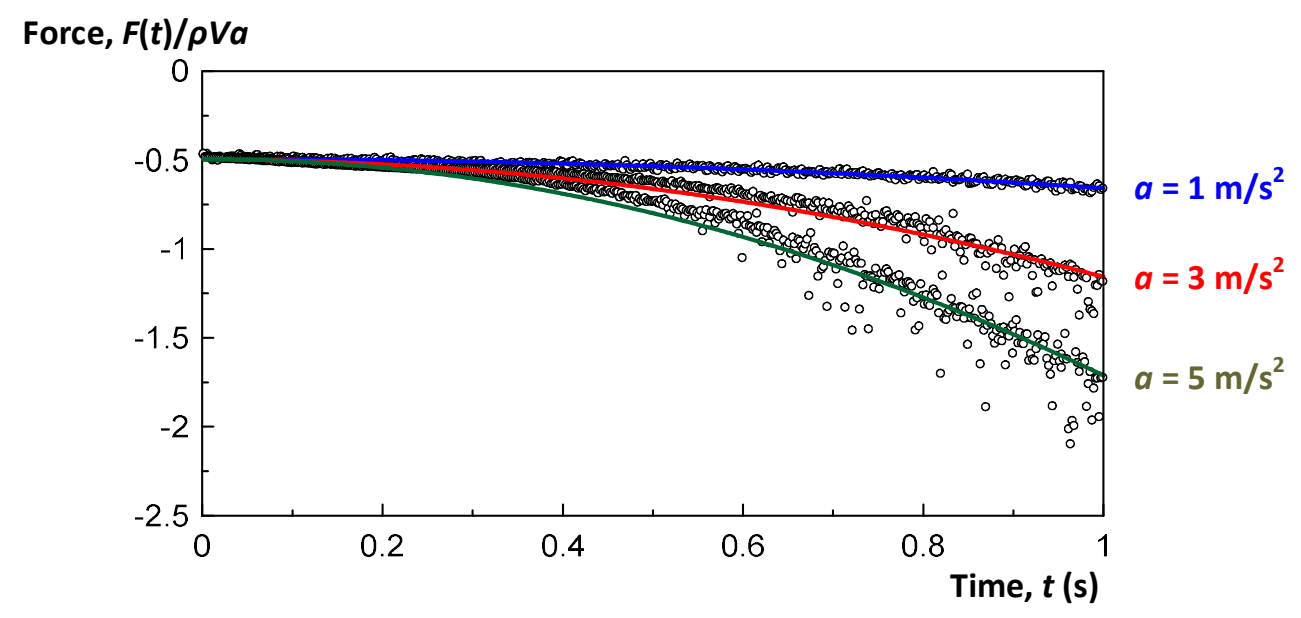

Figure 10. Variation of the external force $F(t)$ within the $1 \mathrm{~s}$ interval with different linear acceleration $a$.

Besides, from the results of analytical derivation and numerical simulation for a smooth sphere, the added mass coefficient $C_{a}$ (as well as the added mass $m_{a}$ ) is independent from the initial acceleration a applied to the object. 


\section{Results and discussion}

\subsection{Single Nozzle-Diffusor Duct (NDD) Anchored to the Seabed}

To simulate a single nozzle-diffusor duct (NDD) with two wings on the two sides, built-in functions, "Shape," "6D Buoy," and "Wings," of OrcaFlex were used to construct the model. The "Shape" function assembles 80 pieces of thick plates of different inner and outer diameters to form the duct. Material and hydrodynamic properties of the duct were then estimated by using another function called "6D Buoy." The two wings, which were $2.5 \mathrm{~m}$ long with the profile of NACA 6409 , were attached to the duct body by using the function "Wings." A step-by-step procedure to construct the duct and set up all the needed parameters was attached as Appendix of this paper. It is noted that the lift and drag coefficients of the two wings were obtained by XFOIL and used in the program. Figure 11 shows the diagram of the duct used in OrcaFlex.

(a)

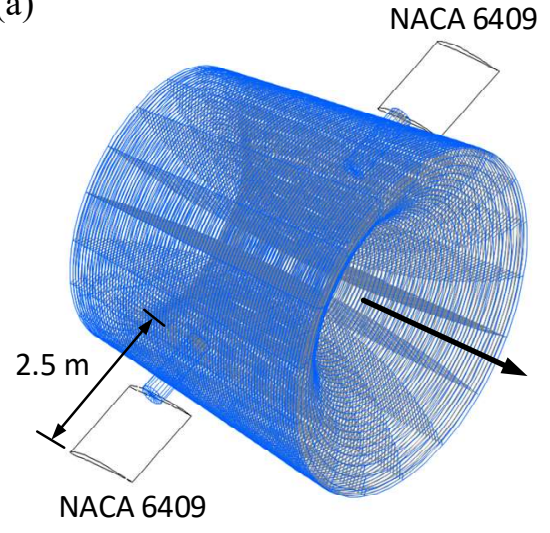

(b)

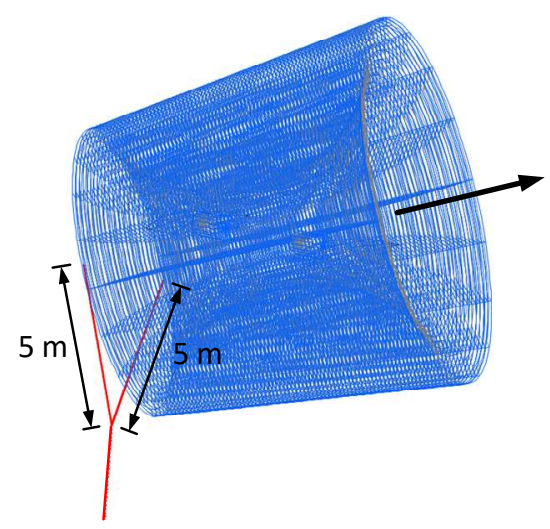

Figure 11. Duct model in OrcaFlex.

The mooring system consisted of one main line of $200 \mathrm{~m}$ and two short lines of $5 \mathrm{~m}$, forming a $\mathrm{Y}$-shape to anchor the duct to the seabed. The nominal diameter of the three lines were all $0.133 \mathrm{~m}$ as the studless chain used in Kyu (2013). Table 3 lists the mooring line properties and it is noted that the seabed and mooring lines were both assumed frictionless in this study; the drag coefficient in the table was calculated under the condition of no axial drag force on the mooring lines. As illustrated in the schematic diagram (Figure 13), the duct was anchored to the seabed $200 \mathrm{~m}$ below the sea surface. Current speed was assumed $1 \mathrm{~m} / \mathrm{s}$ uniformly throughout the entire water depth. JONSWAP spectra of both normal and storm wave conditions were employed to simulate the wave conditions in the Taitung offshore area (Lai, 2015).

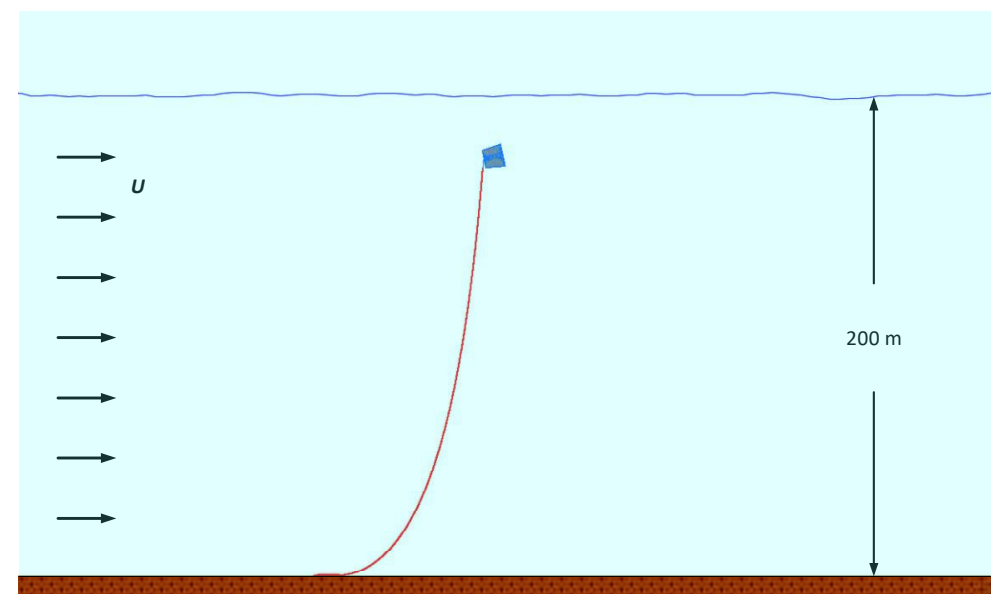

Figure 12 Illustration of single duct anchored on the seabed. 
Table 3. Mooring line properties

\begin{tabular}{ll} 
Nominal diameter $(\mathrm{m})$ & 0.133 \\
Diameter $(\mathrm{m})$ & Outer $=0.24$; Inner $=0$ \\
Bending stiffness $\left(\mathrm{kN} \cdot \mathrm{m}^{2}\right)$ & $\mathrm{X}=0 ; \mathrm{Y}=0$ \\
Axial stiffness $(\mathrm{kN})$ & $1.52 \times 10^{6}$ \\
Weight in air $(\mathrm{kN} / \mathrm{m})$ & 3.473 \\
Displacement $(\mathrm{kN} / \mathrm{m})$ & 0.455 \\
Weight in water $(\mathrm{kN} / \mathrm{m})$ & 3.018 \\
Diameter to weight ratio $(\mathrm{m} / \mathrm{kN})$ & 0.08 \\
Minimum breaking load $(\mathrm{kN})$ & 15984 \\
Poisson ratio & 0.5 \\
Drag coefficient $(\mathrm{no}$ axial drag) & 2.4 \\
Lift coefficient & 0 \\
Added mass coefficient (only axial direction) & 1 \\
Allowable tension $(\mathrm{kN})$ & 15984 \\
\hline
\end{tabular}

\subsubsection{Duct weight and center of gravity}

To obtain high PTO for the energy harvester, the pitch angle (or inclined angle) of the duct between its longitudinal axis and the incoming flow direction needs to be as small as possible. The force system composing of the buoyant force $F_{B}$ (through the center of buoyancy, CB), weight of the NDD $W_{N D D}$ (through the center of gravity, CG), and weight of the mooring lines $W_{\text {mooring }}$ essentially affects and determines the pitch angle. Since the duct was wholly submerged in the water, the buoyant force $F_{B}$ and position of CB could be determined readily; it was found that $\mathrm{CB}$ was on the longitudinal axis ( $x$-axis) and $4.27 \mathrm{~m}$ to the duct entrance, as shown in Figure 13(a). The weight of the duct $W_{N D D}$ was then assumed as a fraction of $F_{B}$, namely the buoyant force that the duct sustains when wholly submerged in the water. With a fixed weight of the mooring

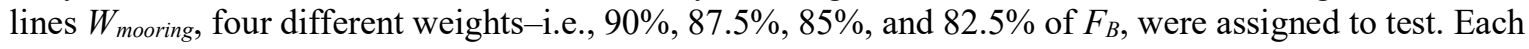
$W_{N D D}$ formed a force-equilibrium system with $F_{B}$ and $W_{\text {mooring }}$ of the mooring lines to the seabed. As depicted in Figure 13(b), a pitch angle $\theta$ existed in the equilibrium system.

(a)

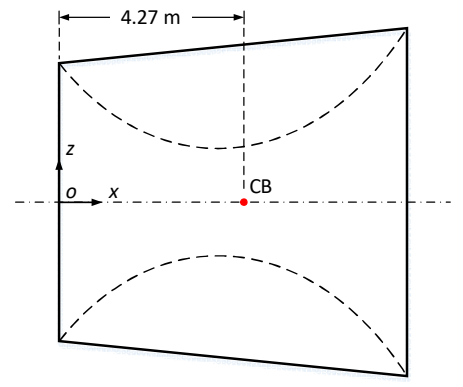

(b)

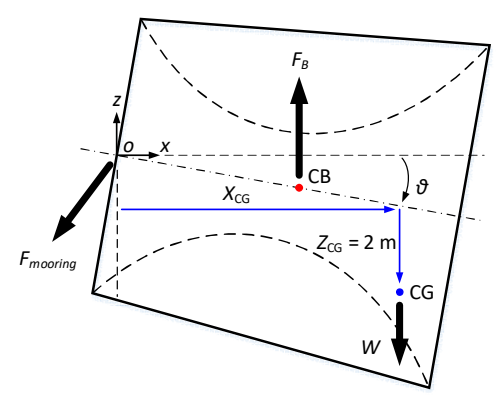

Figure 13. (a) CB position on the local coordinate system of the duct model; (b) force balance and the corresponding position of CG.

Sudhamshu et al (2013) indicated that the pitch angle $\theta$ needed to be small; $90 \%$ of the power take-off for zero pitch angle could be obtained when $\theta$ was controlled smaller than $5^{\circ}$. Since the magnitude of $\theta$ depended on the position of CG, their relation of each duct weight $W_{N D D}$ was examined. As the duct was symmetric, CG was naturally on the $x-z$ plane. Moreover, to keep the duct stable, the vertical position $Z_{\mathrm{CG}}$ of $\mathrm{CG}$ was assumed at $2 \mathrm{~m}$ beneath the $\mathrm{x}$-axis, where $\mathrm{CB}$ resided. Figure 14 examines the resulting pitch angle $\theta$ 
against the horizontal position $X_{\mathrm{CG}}$ of CG for each duct weight. It was found that the pitch angle $\theta$ was about $70^{\circ}$ counter-clockwise for each duct weight when the horizontal distance to the duct entrance of CG, $X_{\mathrm{CG}}=0$. As the distance $X_{\mathrm{CG}}$ increased, the pitch angle $\theta$ started to decrease for the duct to rotate in the clockwise direction, until $X_{\mathrm{CG}}$ was in the range between $4.5-5.5 \mathrm{~m}$ for the pitch angle $\theta$ reached zero degree.

(a)

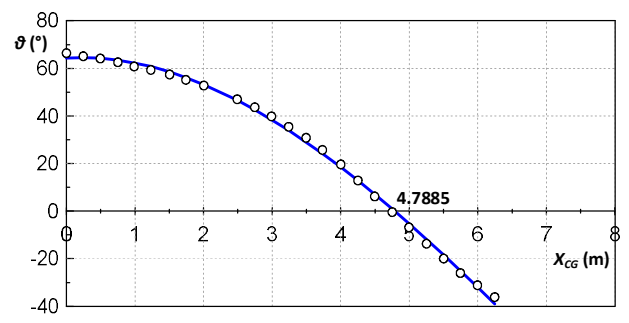

(c)

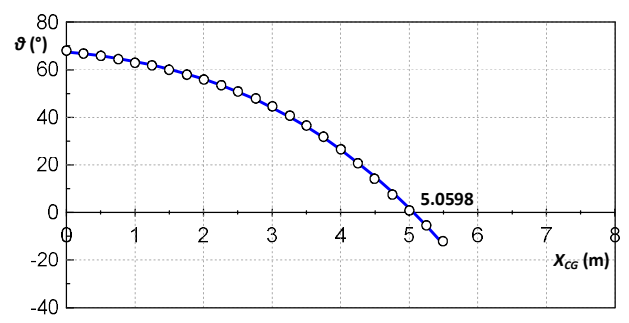

(b)

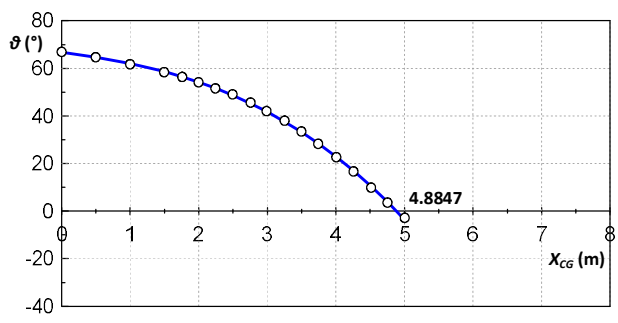

(d)

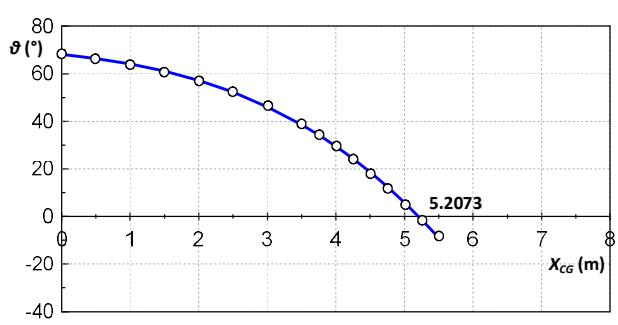

Figure 14. Variation of the pitch angle $\theta$ according to different value of $X_{C G}$ for each duct weight. (a) $90 \%$; (b) $87.5 \%$; (c) $85 \%$; (d) $82.5 \%$ of the duct buoyancy.

The duct could obtain statically equilibrium for each weight by adjusting its CG position. In practice, this adjustment can be executed by changing the weight distribution on the duct. Another aspect for the engineering practice is the submerged depth of the duct. Since the duct was wholly submerged in the water column, and its weight as assigned was only a fraction of the buoyant force, it could reach equilibrium at any submerged depth. By changing the attack angle of its two wings, the resultant lift force against the weight of the duct would then help to adjust the duct position to a predetermined depth. Figure 15(a) shows the experimental result of the neutral position of the duct by different attack angle of the wings (Chen and Huang, 2016, Huang, 2016). The two white dots at each angle were the front and rear LED markers attached to the duct. When the attack angle was fixed, the submerged depth of the duct was then related to the assigned weight $W_{N D D}$. According to the simulation results in Figure 15(b), the submerged depth increased from $25 \mathrm{~m}$ to $100 \mathrm{~m}$ by increasing the weight of the duct from $82.5 \%$ to $90 \%$ of its buoyancy when the attack angle was kept at zero degree. In reality, current speed near water surface is usually greater. The duct with weight of $82.5 \%$ the buoyancy with center of gravity at $4.52 \mathrm{~m}$ to the duct entrance and $2 \mathrm{~m}$ beneath the central axis was then chosen for the later dynamic analysis.

(a)

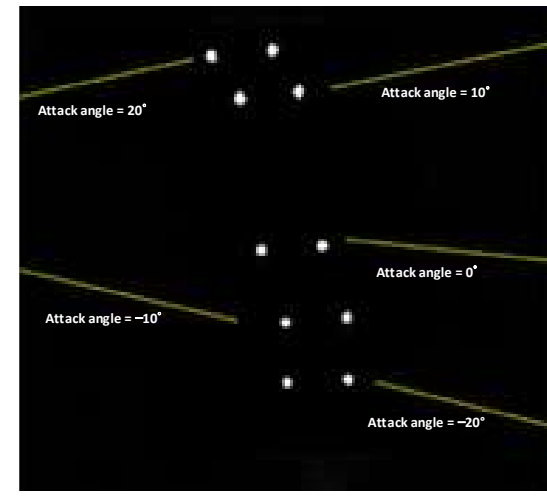

(b)

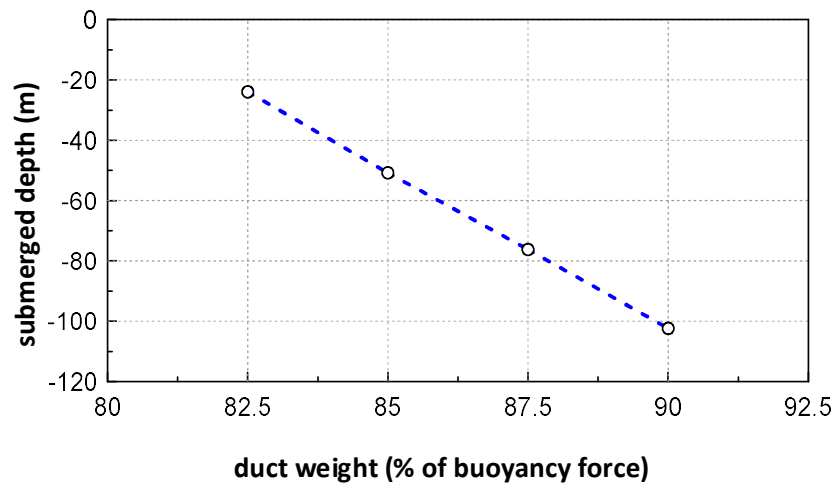

Figure 15. (a) Experimental result for the neutral position of the duct by different attack angle of the wings (Huang, 2016); (b) submerged depth with different design weight of the duct. 


\subsubsection{Responses to waves and current}

The dynamic simulations of proposed duct design were further examined under normal and storm wave conditions. JONSWAP spectra of these two conditions in the Taitung area at the east coast of Taiwan were analyzed by Lai (2015) and the parameters reported were listed in Table 4. Figure 16 shows the wave form of JONSWAP spectrum under the normal wave condition. Wave direction approaching the duct was varied for every $45^{\circ}$ from $0^{\circ}$ to the duct longitudinal axis; each wave direction was tested with uniform current speed of 1 $\mathrm{m} / \mathrm{s}$ parallel to the duct axis. Although the current speed was assumed uniform along the water depth in the simulations, it was more likely faster in the upper layer of water close to the sea surface to have higher value of PTO. In this regard, the duct was assumed initially deployed at the position $25 \mathrm{~m}$ below the sea surface under the normal wave condition.

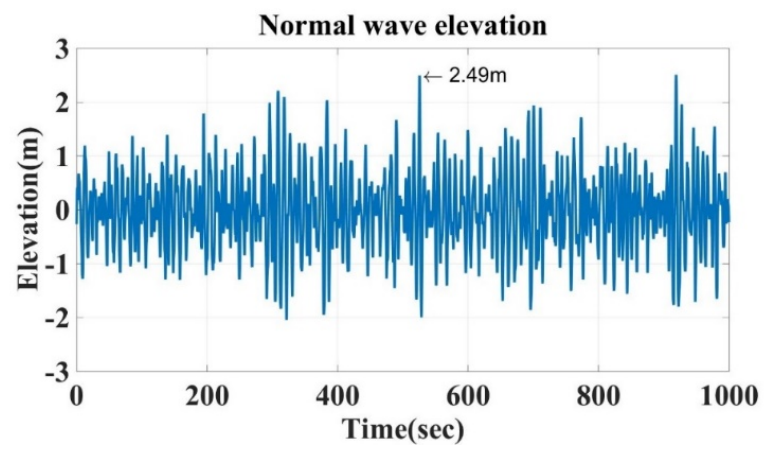

Figure 16. Wave form of JONSWAP spectrum under normal wave condition.

Figures. 17-18 thus demonstrate the translational and rotational responses of the duct. It can be seen that the translational responses (surge, sway, and heave) against different wave directions were all within $1 \mathrm{~m}$.

Similarly, the angles of rotational responses (roll, pitch, and yaw) were also small. These results indicate that the duct was stable to harvest ocean current energy at $25 \mathrm{~m}$ beneath the sea surface under normal wave condition.

(a) Surge $(m)$

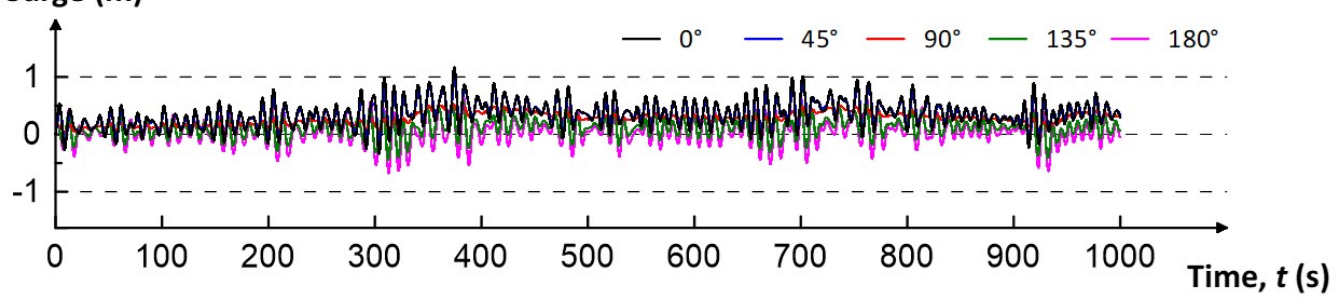

(b) Sway (m)

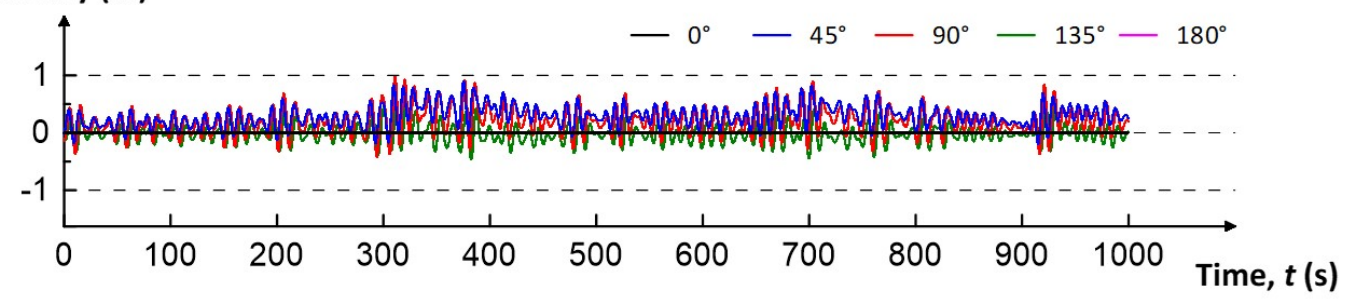


(c)

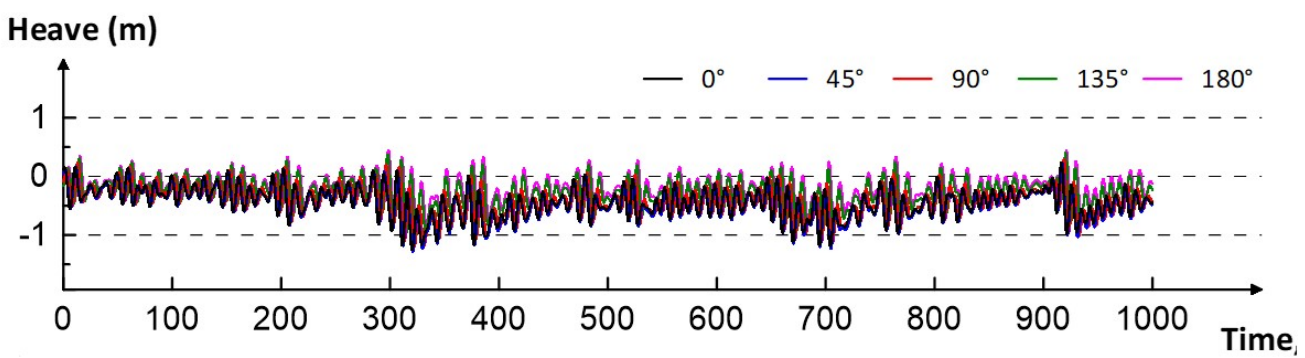

Figure 178. Translational responses against different approaching wave directions under normal wave conditions. (a) Surge; (b) Sway; (c) Heave.

(a)

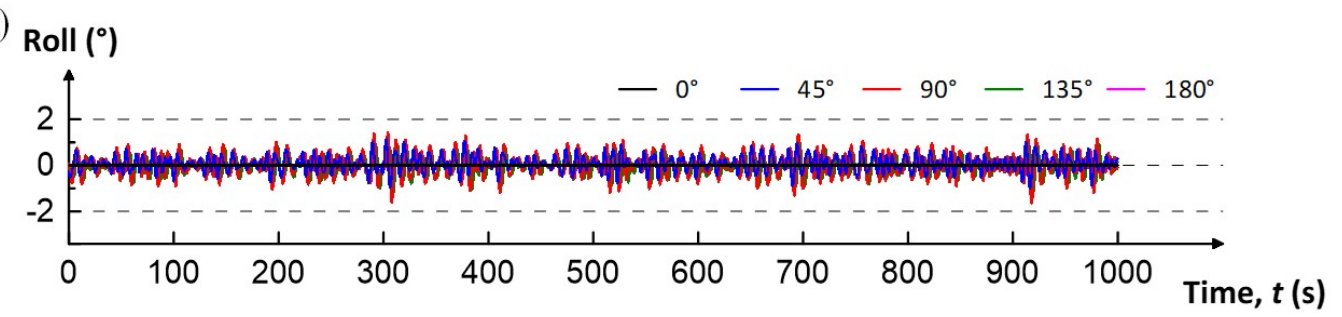

(b) Pitch ( $\left.{ }^{\circ}\right)$

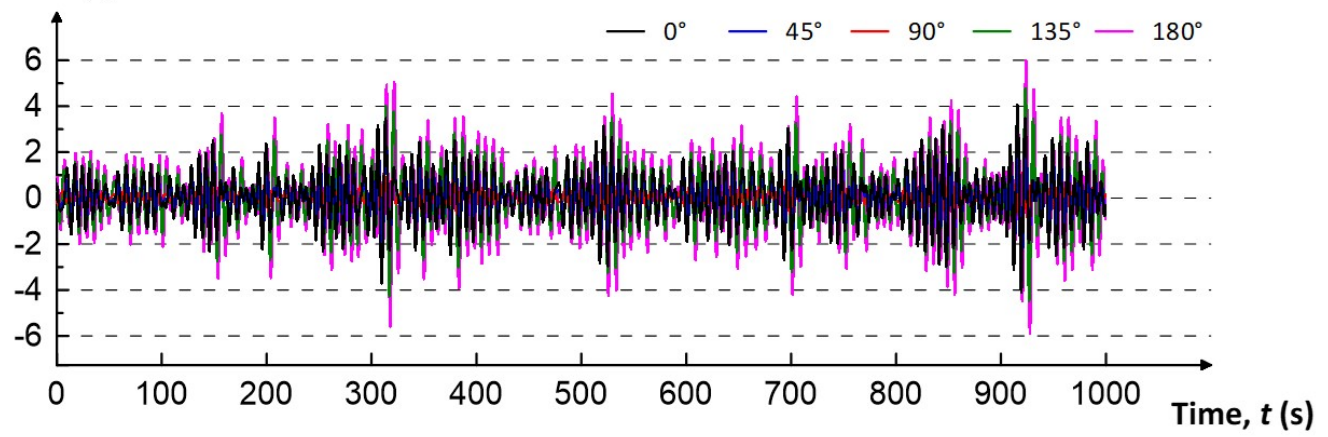

(c) Yaw ( $\left.{ }^{\circ}\right)$

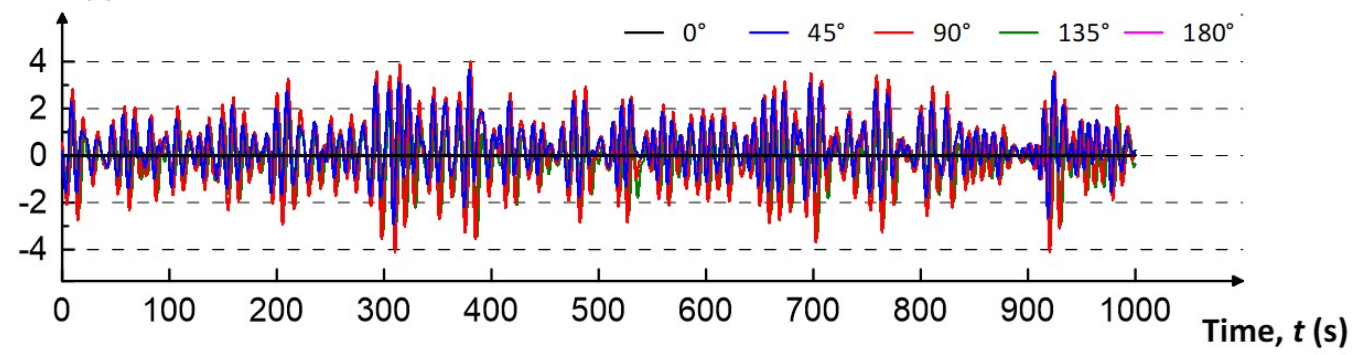

Figure 18. Rotational responses against different approaching wave directions under normal wave conditions.

(a) Roll; (b) Pitch; (c) Yaw.

Every year there are usually several typhoons hitting Taiwan during summer. The historical typhoon tracks in Figure 19 shows that about eighty percent of the typhoons arrive Taiwan from the east, and their routes usually cross the path of Kuroshio current which flows north along the east coast of Taiwan. Therefore, the stability test of the duct under storm wave condition mainly focused on the $90^{\circ}$ wave direction. The storm waves were also generated from JONSWAP spectrum as shown in Figure 20 and Table 4. Test results revealed that the duct underwent both large translational (surge, sway, and heave) and rotational (roll, pitch, 
and yaw) motions under the storm wave condition. All the translational responses (Figure 21) reached as high as 4-6 $\mathrm{m}$, while the rotational responses, particularly yaw, exceeded $10^{\circ}$ (Figure 22). This indicates that the duct needs to sink into deeper water depth to avoid such huge responses and keep the duct stable.

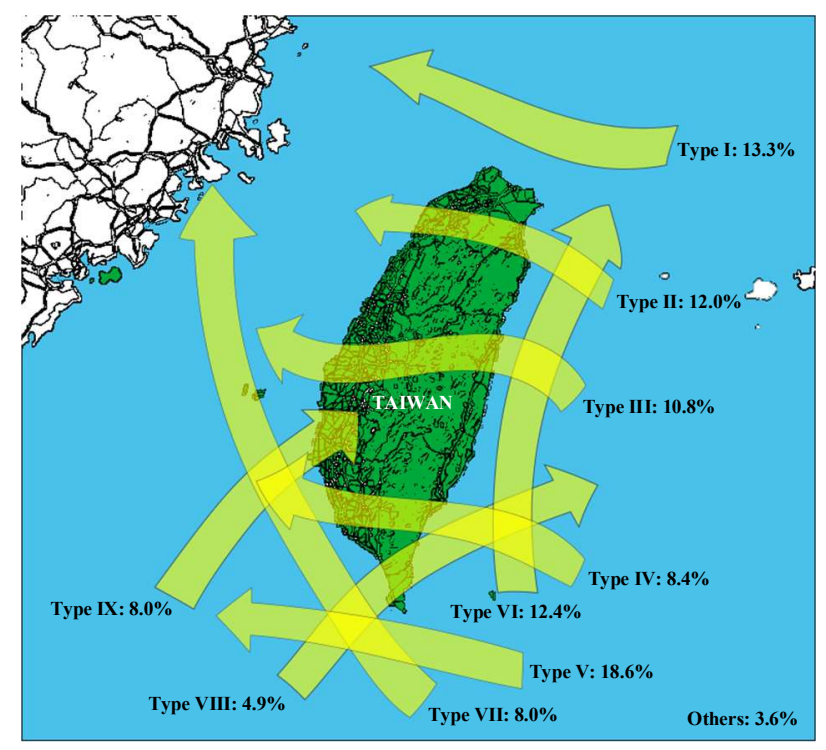

Figure 19. Historical typhoon tracks around Taiwan from 1897-2017.

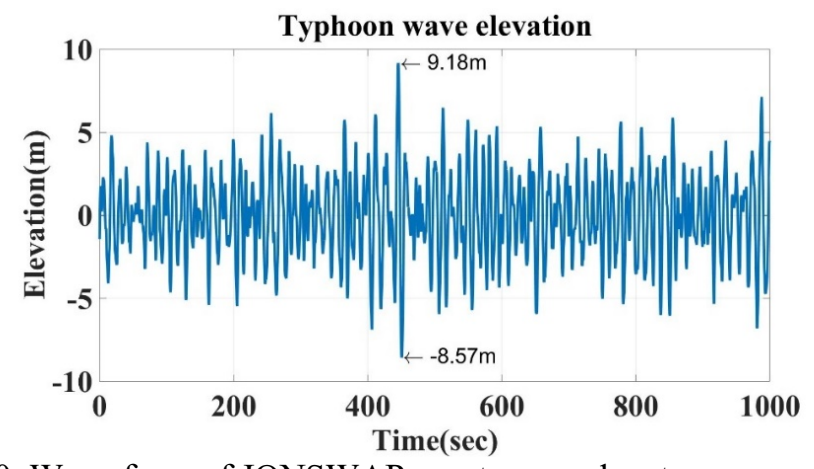

Figure 20. Wave form of JONSWAP spectrum under storm wave condition.

Table 4. JONSWAP parameters for normal and storm wave conditions around the Taitung area

\begin{tabular}{cccc}
\hline & $\gamma$ & $\alpha$ & $f_{p}$ \\
\hline Normal wave condition & 1.59 & 0.0151 & 0.094 \\
Storm wave condition & 1.22 & 0.0047 & 0.105 \\
\hline
\end{tabular}

Both the translational and rotational responses diminished as the duct dived into deeper water. At $100 \mathrm{~m}$ below sea surface, all the translational responses were less than $1.5 \mathrm{~m}$ and all the rotational responses smaller than $5^{\circ}$ (not shown here). The duct demonstrated high stability and capability of obtaining high PTO. Since the yaw of the duct exhibited as the largest movement among the three rotational responses, its variation at different water depth against $90^{\circ}$ storm waves was examined. As shown in Figure 23, the heading angle of yaw decreased as the submerged depth of duct increased, from larger than $10^{\circ}$ at $60 \mathrm{~m}$ to smaller than $5^{\circ}$ at 90 $\mathrm{m}$ below the sea surface. Since the duct would obtain large PTO when its rotational response is smaller than $5^{\circ}$, it is then contemplated that the duct should dive into a depth at least $90 \mathrm{~m}$ below the sea surface under storm wave condition. 
(a)

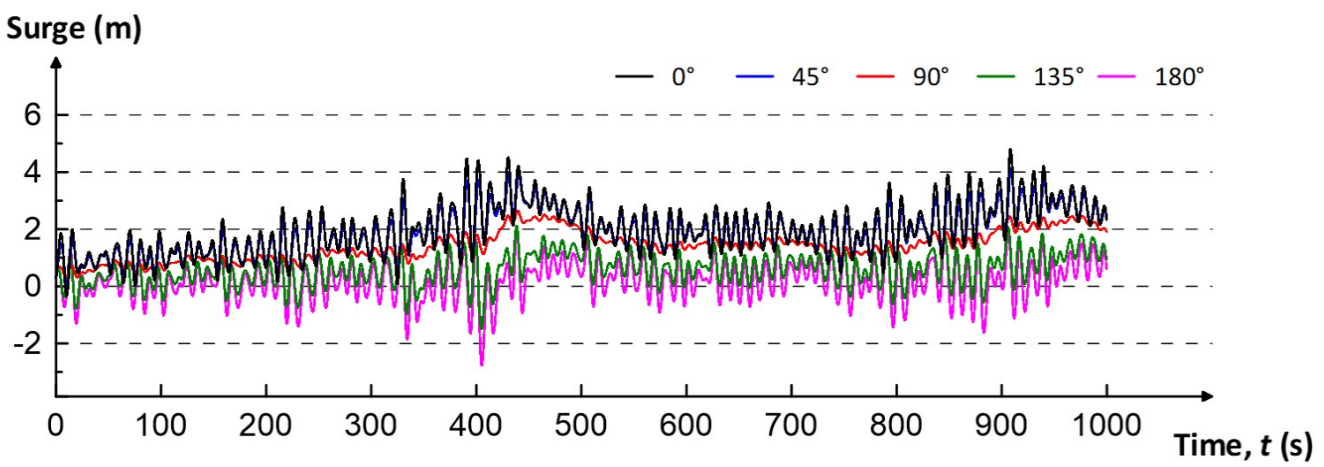

(b)

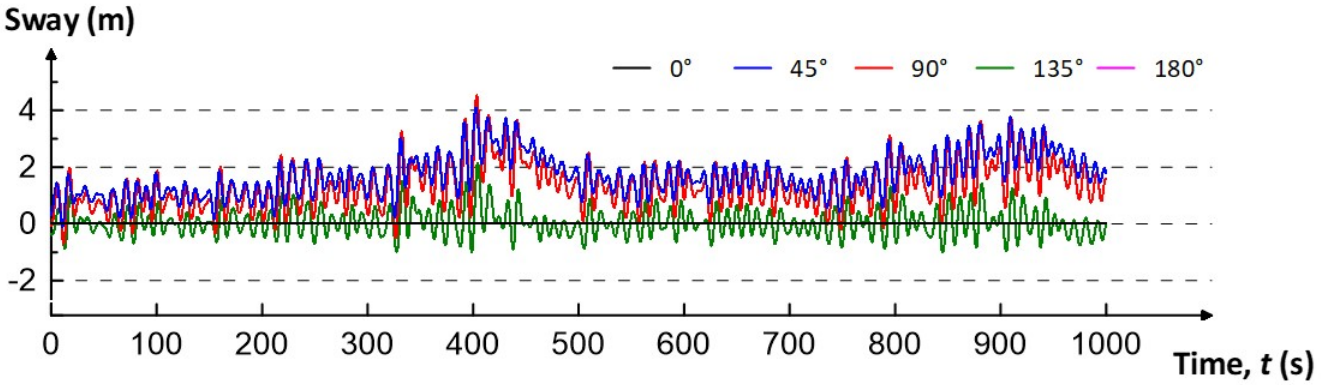

(c) Heave (m)

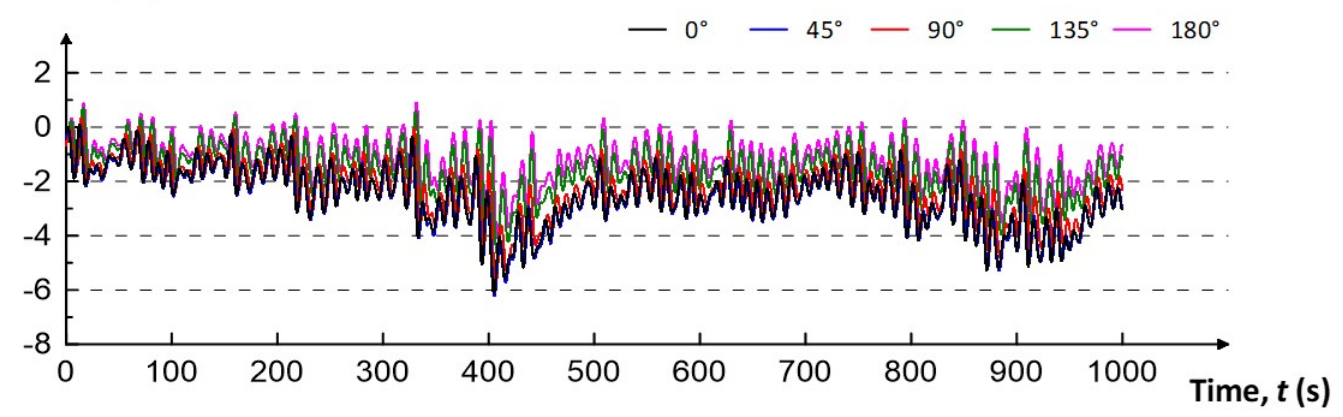

Figure 21. Translational responses against different approaching wave directions under storm wave conditions. (a) Surge; (b) Sway; (c) Heave. Duct is at $25 \mathrm{~m}$ below sea surface. 
(a)

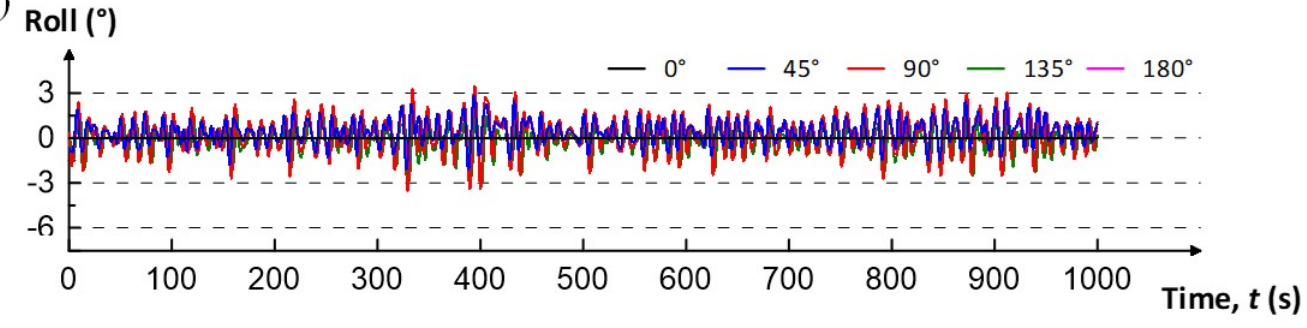

(b)

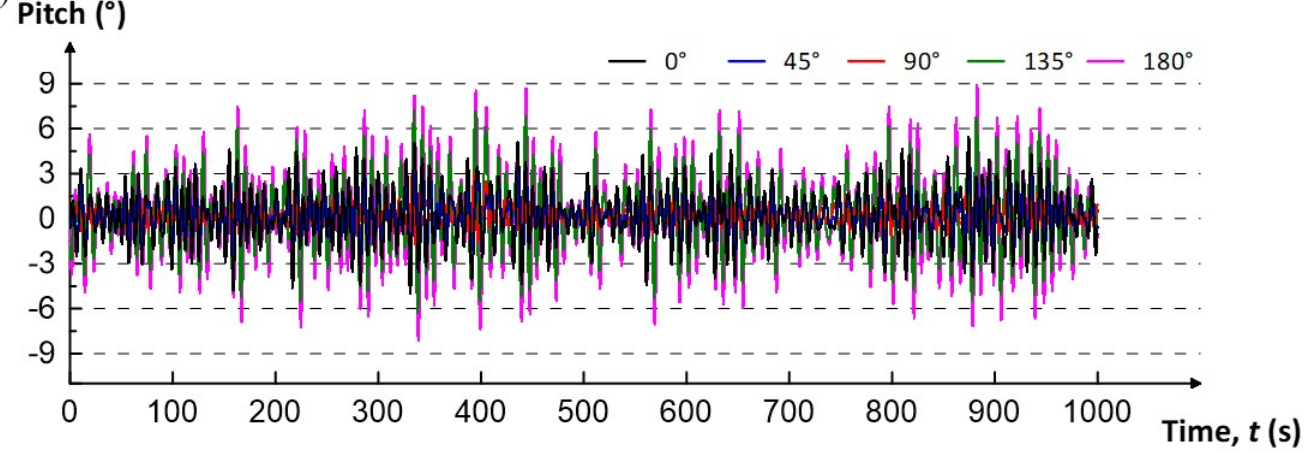

(c)

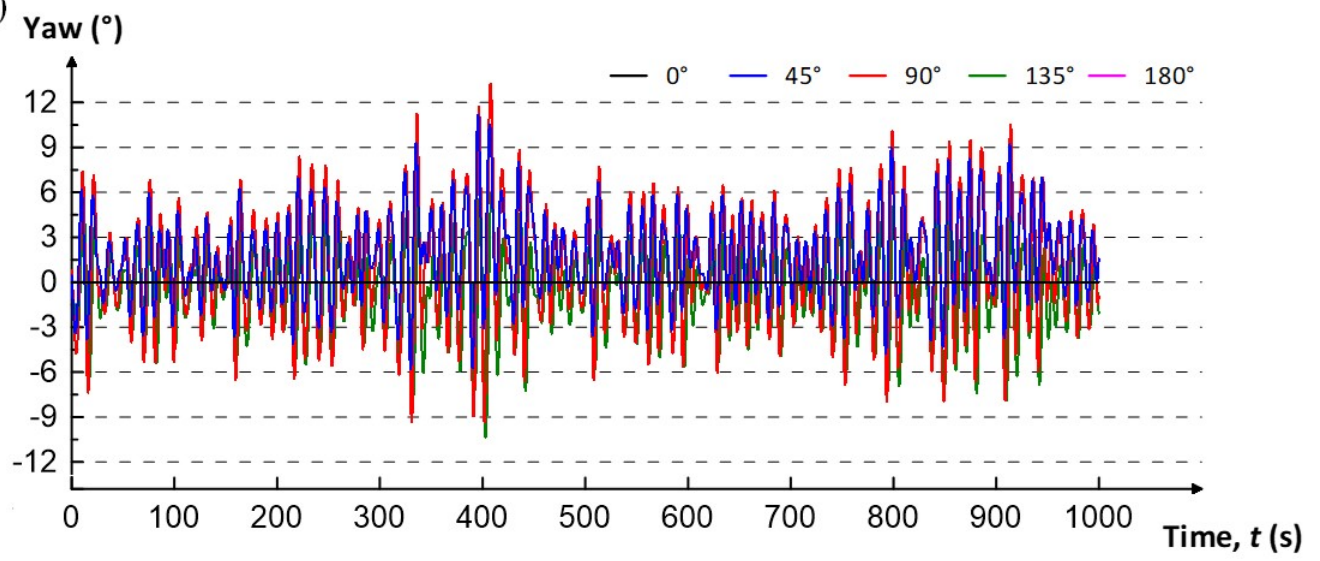

(d)

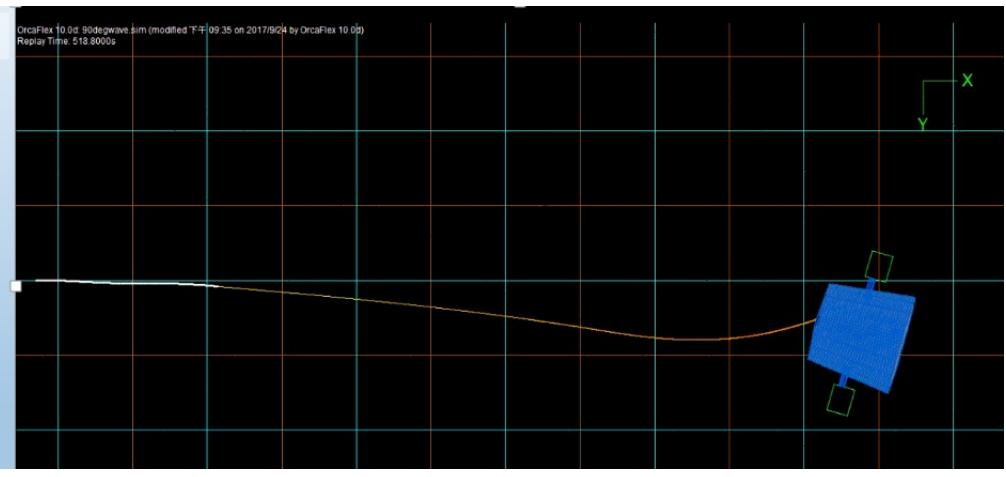

Figure 22. Rotational responses against different approaching wave directions under storm wave conditions. (a) Roll; (b) Pitch; (c) Yaw; (d) Orcaflex simulation. Duct is at $25 \mathrm{~m}$ below sea surface. 


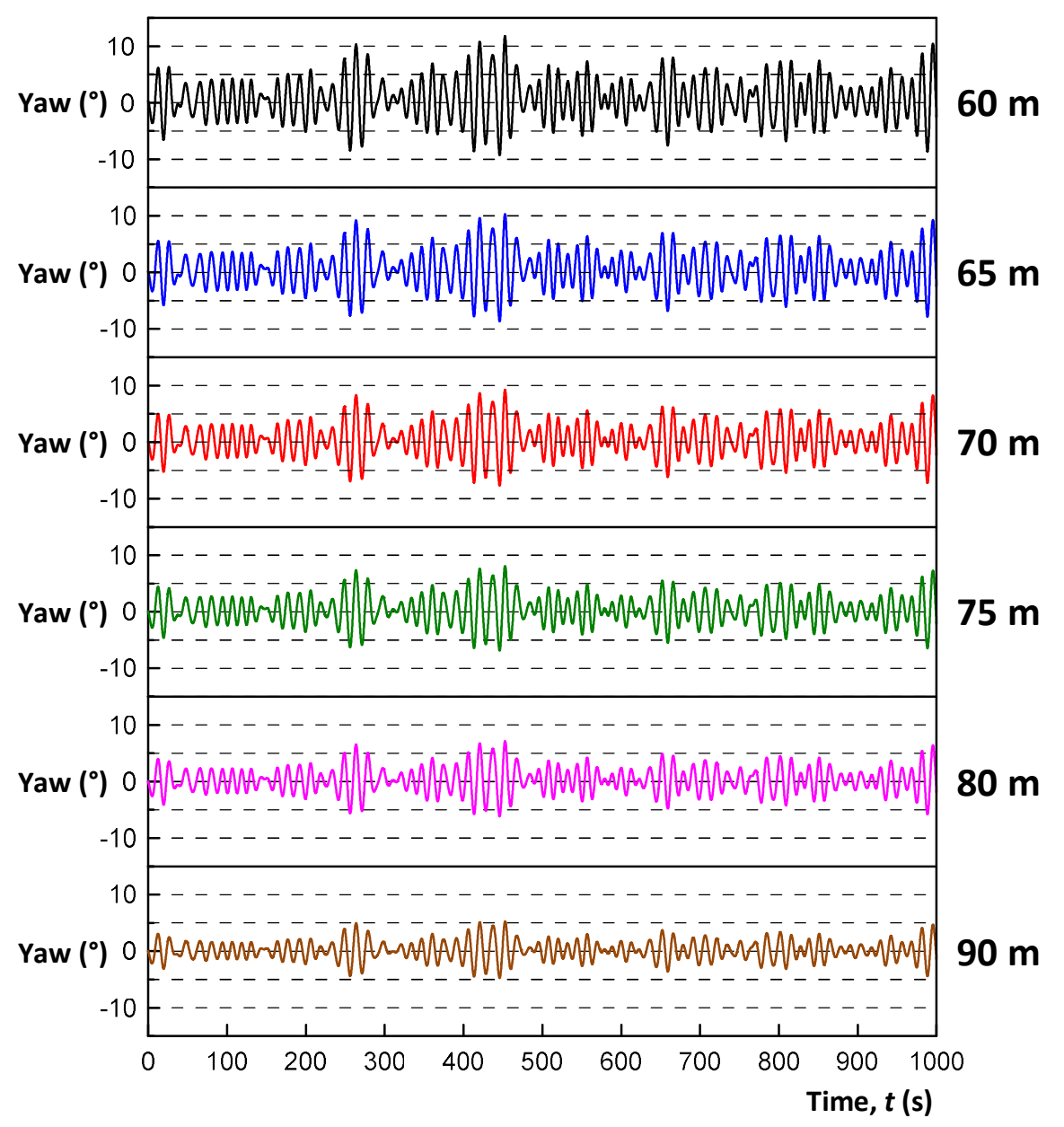

Figure 23. Variation of yaw at different water depth against $90^{\circ}$ storm waves.

We define the dimensionless displacement of the duct motion $(\zeta)$ by normalized the duct displacement by the duct length. The dimensionless submerged depth $(\xi)$ is defined as the ratio of the submerged depth to the wave height of the storm wave. Figure 24 depicts the dimensionless displacements of surge, sway and heave motion of duct versus the dimensionless submerged depth. The figure also shows the rotation of roll, pitch and yaw motions of the duct versus the dimensionless submerged depth. The efficiency of PTO of the duct may retain high value when the rotations of pitch and yaw motion are less than 10 degrees. The figure clearly describes the stability of the duct under storm wave is quite related to the dimensionless submerged depth and the high efficiency of PTO may sustain when the dimensionless submerged depth is larger than 7.4. We, however, would like to suggest the duct should submerge deeper $(\xi>9)$ and the energy harvester can stably collect current energy. 

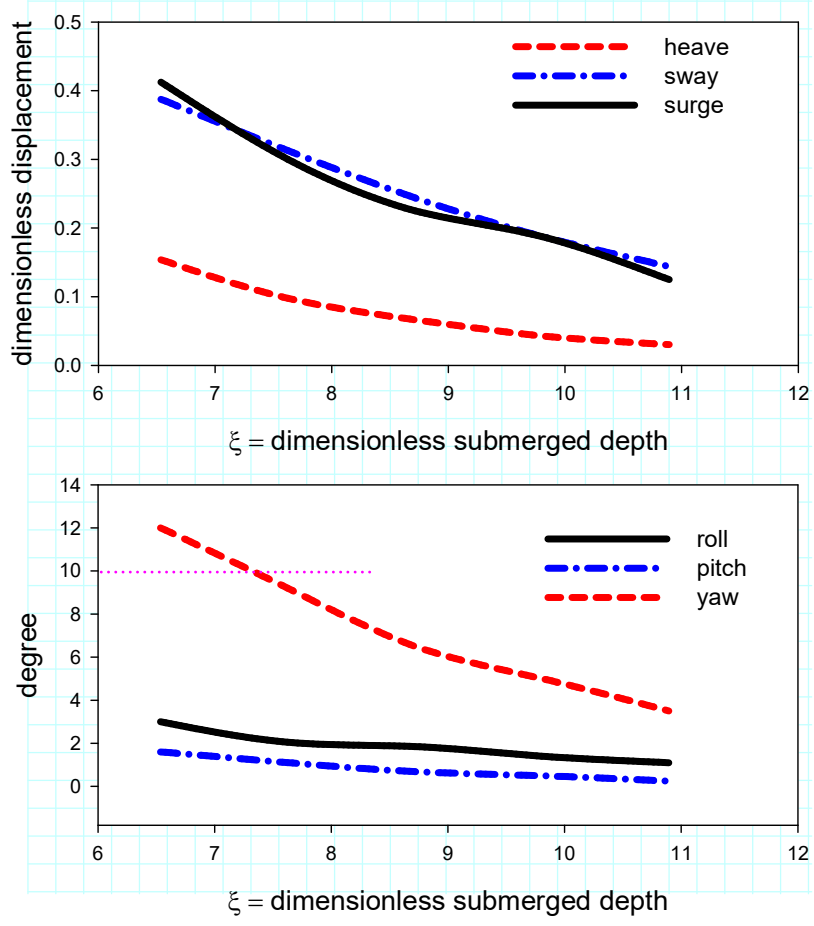

Figure 24 The dimensionless response of duct versus dimensionless submerged depth

\subsection{Megawatt Kuroshio Energy Harvesting System}

In 2013, a research team composed of three universities in Taiwan, NSYSU (National Sun Yat-sen University), KYU (Kao Yuan University), and NKMU (National Kaohsiung Marine University) deployed a semi-submerged platform carrying a square nozzle-diffuser duct (Chen et al. 2018). The peak power take-off (PTO) received from this field test was up to $5 \mathrm{~kW}$. An optimized circular nozzle-diffuser duct designed (as shown in Figure 25) was studied by Huang (2016) and they equipped with NACA 6409 turbine blades, the simulation results showed that the new energy harvester could obtain three times the PTO than the previous square one under the condition of $1 \mathrm{~m} / \mathrm{s}$ current speed. Thus, it might be reasonable to assume the possible maximum PTO for the optimized circular nozzle-diffuser duct (NDD) would be more than $15 \mathrm{~kW}$ when the duct is deployed in the marine environment of Kuroshio, of which the current speed is usually larger than 1 $\mathrm{m} / \mathrm{s}$. From the simulation results in the previous section, a single NDD anchored to the seabed could maintain stable and obtain $90 \%$ PTO if it stays at least $90 \mathrm{~m}$ below the sea surface under normal and storm wave conditions. Totally 70 of this type of ducts can generate electricity equivalent to a megawatt-level power plant.

However, the water depth of this study was set as $200 \mathrm{~m}$, but the installation cost would increase dramatically if the water depth becomes $500 \mathrm{~m}$. Thus, anchoring 70 NDDs to the seabed at the same time is impracticable, whereas some type of platform is needed to carry these ducts. Figure 26 illustrates a conceptual diagram of spar-type platform and the feasibility and dynamic analyses of this spar platform has been preliminary studied (Yeh et al 2021) and we can expect that to deploy a Megawatt Kuroshio power plant is possible in the near future. 
(a)

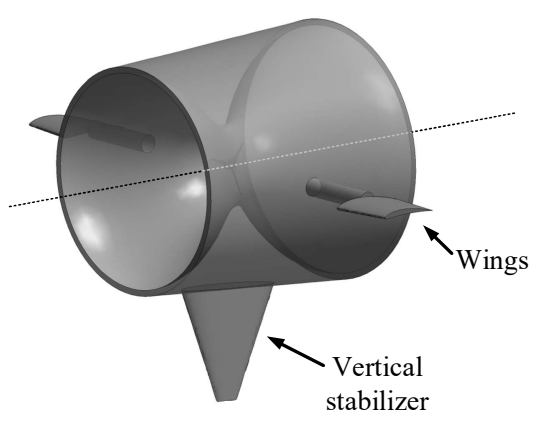

(b)

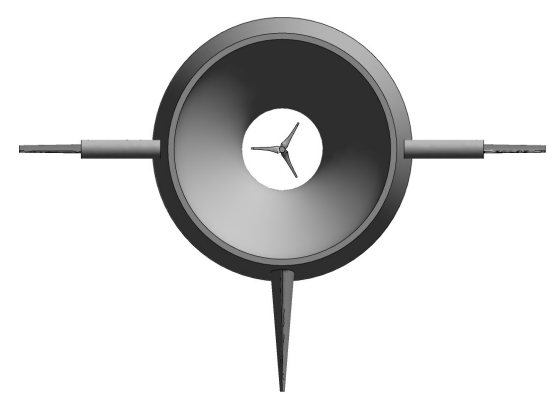

Figure 25. (a)\&(b) Optimized circular nozzle-diffuser duct designed by harmony search method. [5]

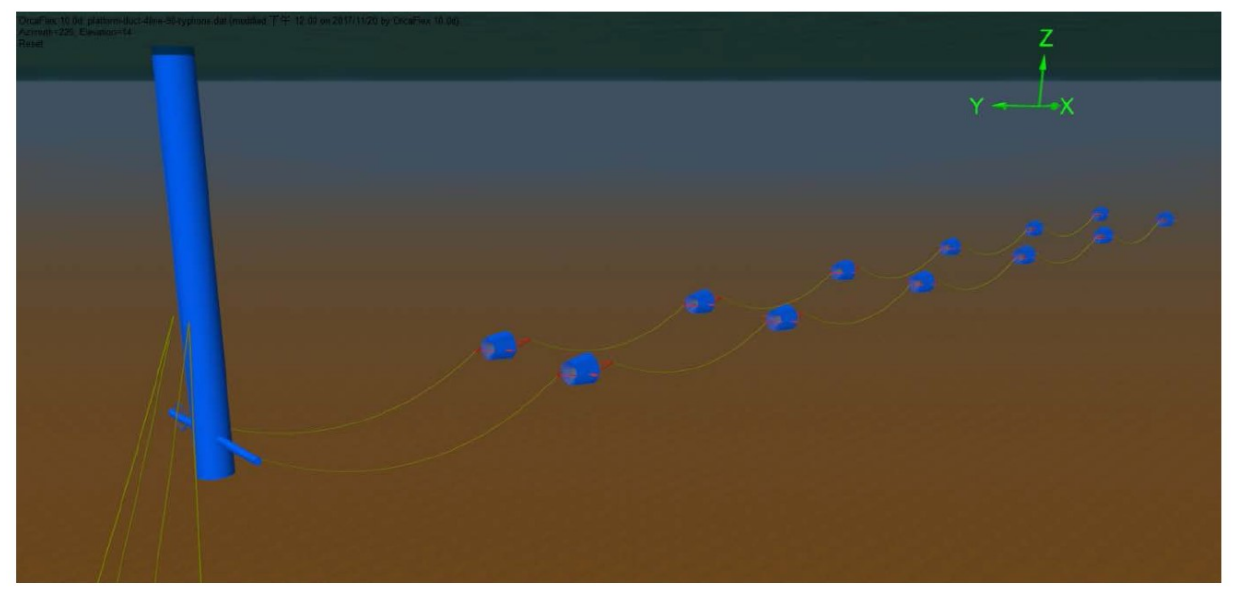

Figure. 26. The conceptual diagram of the spar platform (Yeh et al 2021).

\section{Conclusion}

This study proceeded a feasibility study for an energy harvester, an optimized circular nozzle-diffusor, deployed in the marine environment of Kuroshio currents. By using ANSYS Fluent and OrcaFlex, dynamic simulations of a single duct anchored to the seabed under normal and storm wave conditions with constant 1 $\mathrm{m} / \mathrm{s}$ current speed were conducted. Some remarks were drawn as following:

1. The hydrodynamic coefficients, including $C_{d}$ and $C_{a}$ of the duct in translational and rotational motions, were calculated. The rotational domain was verified in this study with the domain length and diameter as $40 \mathrm{~m}$ and 9D m. Two methods were compared to verify the accuracy of $C_{d}$, and the results agrees well, which means the data for $C_{a}$ from the acceleration method was also confirmed.

2. The drag and added mass coefficients of the duct for translational and rotational motions were calculated by using an acceleration method. Assigning a constant linear or angular acceleration to the duct to initiate movement or rotation, the resultant external force and moment within a short period of time were then used to calculate the coefficients.

3. The duct model for the simulation was constructed by OrcaFlex. Weight of the duct was defined as fraction of its buoyant force. After different weight was assigned to the duct, functional relation between the position of center of gravity of the duct and the resultant pitch angle was established.

4. Simulation results showed that the duct was stable under normal wave condition, even when its submerged depth was small. Under storm wave condition, however, large responses in all 6DoF motions were observed when the duct was close to the sea surface. All the translational responses 
reached as high as 4-6 m, while the rotational responses, particularly yaw, exceeded $10^{\circ}$. It indicated that the duct needed to dive into deeper water depth to sustain the stability of the duct under storm wave condition.

5. All the translational and rotational responses diminished as the duct dived into deeper water; the translational movements were less than $1.5 \mathrm{~m}$ and the rotational angles smaller than $5^{\circ}$ under $90^{\circ}$ storm wave condition when the submerged depth of duct was $100 \mathrm{~m}$ below the sea surface. The duct demonstrated high stability and capability of obtaining high PTO. Since the duct would obtain large PTO when its rotational response is smaller than $5^{\circ}$, it is then contemplated that the duct should dive into a depth at least $90 \mathrm{~m}$ below the sea surface under storm wave condition.

6. The proposed energy harvester for Kuroshio power is feasible. To generate electricity as a megawatt power plant, 70 NDDs are needed to anchor to the seabed at the same time. To make the idea more practicable, some type of platform acting as a carrier to reduce construction cost is anticipated. Conceptual design of a spar platform is then suggested.

\section{Acknowlegement}

The study is partially supported by a grant from T-4 University Union of Taiwan.

\section{APPENDIX}

Step-by-step procedure to construct a NDD in OrcaFlex:

Step 1: Set environmental conditions.

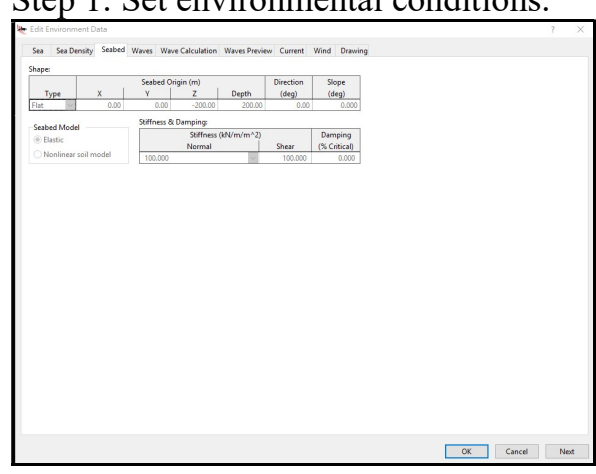

Step 2: Set object parameters in 6D Buoys.

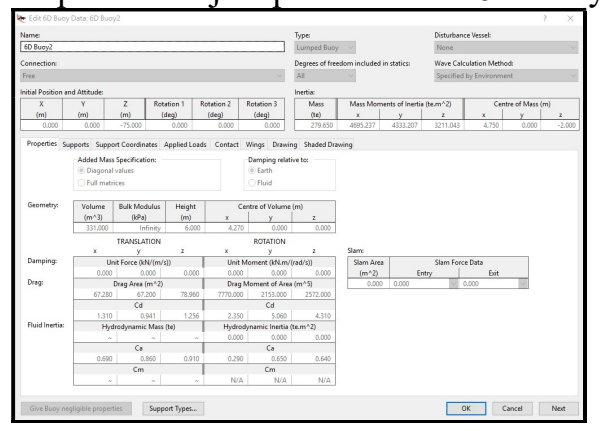

Step 3: Add a winch to connect the object and mooring line. 


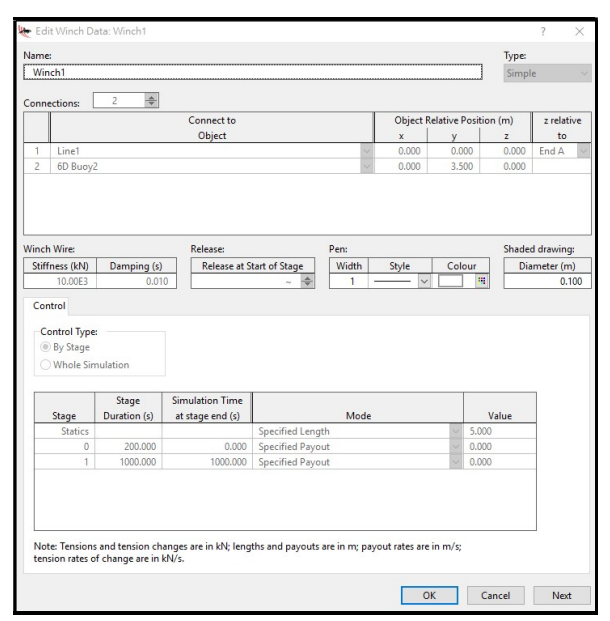

Step 4: Set parameters for mooring line.

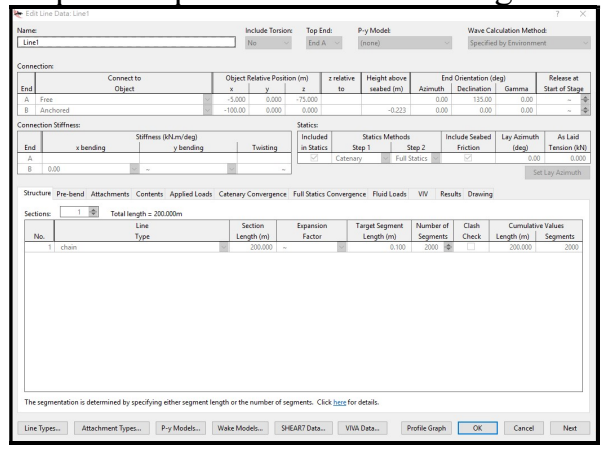

Step 5: Set mooring line properties.

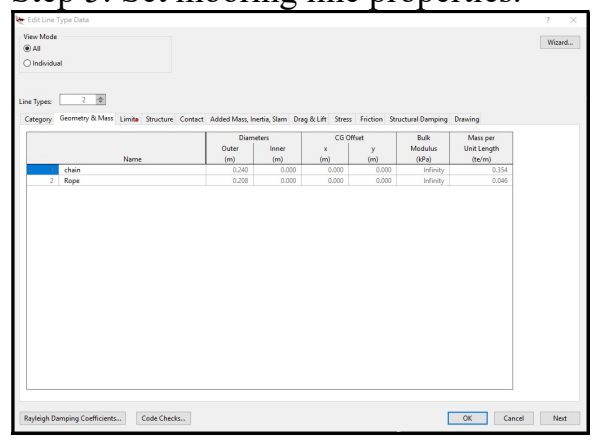

Step 6: Draw the object by Shape (optional). 


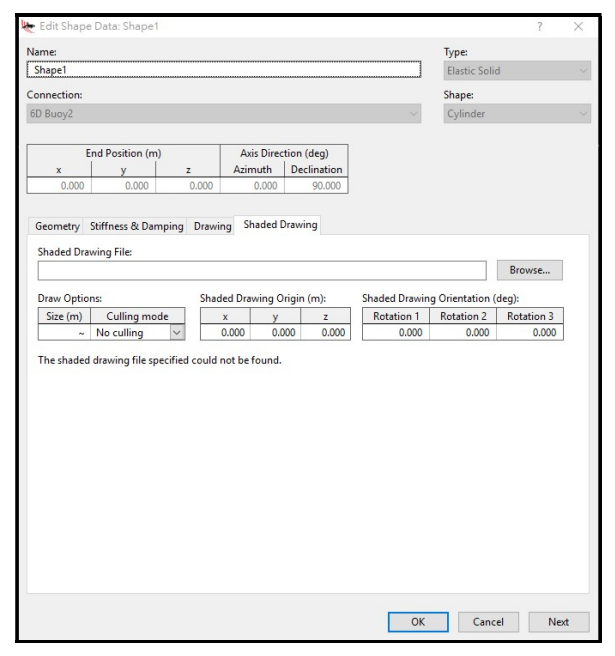

Step 7: Set general settings for the simulation.

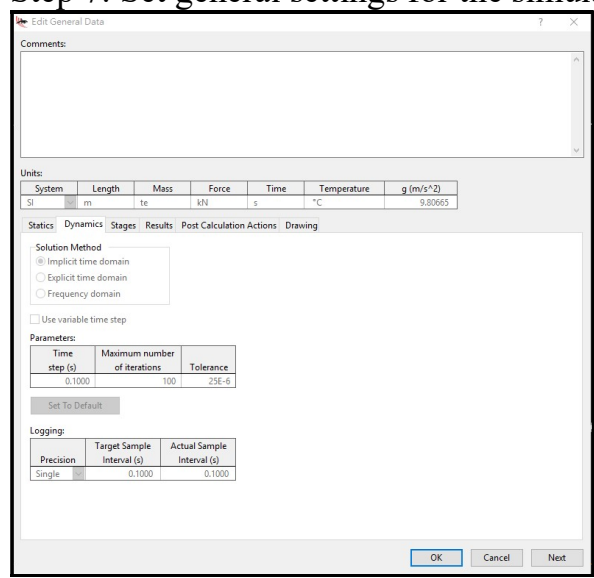

Step 8: Execute the simulation.

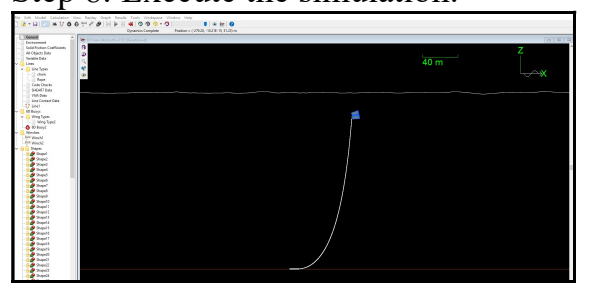

\section{References}

Bedard, R. (2006). Overview: EPRI Ocean Energy Program, The Possibilities in California. Electric Power Research Institute, California.

Bureau of Energy, Ministry of Economic Affairs, Taiwan (2019). Renewable electricity Capacity \& Generation. Retrieved from

https://www.moeaboe.gov.tw/ECW/populace/web_book/wHandWebReports_File.ashx?type=pdf\&book _code $=$ M_CH\&chapter_code $=$ L\&report_code $=02$

Chen, F. (2010). Kuroshio Power Plant Development Plan. Renewable and Sustainable Energy Reviews, 14(9), 2655-2668.

Chen, Bang-Fuh, and Huang, Cheng-Wei (2016). Nozzle and Diffuser in Drifting Horizontal Turbine Flow. Proceedings of the 26th International Ocean and Polar Engineering Conference. International Society of 
Offshore and Polar Engineers.

Chen, Y.-Y., Hsu, H.-C., Bai, C.-Y., Yang, Y., Lee, C.-C., Cheng, H.-K., Shyue, S.-W., Li, M.-S., and Hsu, C.-J. (2016). Evaluation of Test Platform in the Open Sea and Mounting Test of KW Kuroshio PowerGenerating Pilot Facilities. Proceedings of the 2016 Taiwan Wind Energy Conference. (in Chinese)

Chen, B.-F., Chen, L.-C., Huang, C.-C., Jiang, Z.L., Liu, J.-Y., Lu, S.-Y., Leu, S.-S., Tien, W.-M., Tsai, D.M., and $\mathrm{Wu}$, S. (2018). The Deployment of the First Tidal Energy System in Taiwan. Ocean Engineering, 155, 261-277.

Cummins W E, (1962), The impulse response function and ship motions. Schiffstechnik, 9, 101- 109.

David Corson, D. Todd Griffith, Tom Ashwill, Farzin Shakib, Investigating Aeroelastic Performance of Multi-MegaWatt Wind Turbine Rotors Using CFD, Technical Report, Sandia National Laboratories, 2012

Vinícius Guimarães Monteiro, Edson Luiz Zaparoli, Cláudia Regina de Andrade and Rosiane Cristina de Lima, Numerical Simulation of Performance of an Axial Turbine First stage, JATM, 2012

Huang, C.-W. (2016). Optimal Design of a Nozzle and Diffuser Duct. Master Thesis, National Sun Yat-sen University, Taiwan.

Muiruri Patrick Irungu, Oboetswe Seraga Motsamai, Rehema Ndeda, (2019) A comparative study of RANS-based turbulence models for an upscale wind turbine blade, SN Applied Sciences (2019) 1:237 | https://doi.org/10.1007/s42452-019-0254-5

Kyu, S. P. (2013). Fatigue Performance of Deep Water Steel Catenary Riser. Master Thesis, Pohang University of Science and Technology.

Lai, R.-Y. (2015). Study on the Spectral Properties of Typhoon Generated Waves in Deep Sea. Master Thesis, National Taiwan Ocean University, Taiwan.

Lo, H,-Y. (2017). Dynamic Analysis of Current Turbine System. Master Thesis, National Taiwan Ocean University, Taiwan.

Minesto, Deep Green Technology. [cited 2017; Available from: https://minesto.com/]

NEDO, New Energy and Industrial Technology Development Organization. [cited 2017; Available from: http://www.nedo.go.jp/english/news/AA5en_100269.html]

Sudhamshu A.R., Manik Chandra Pandey, Nivedh Sunil, Satish N.S., Vivek Mugundhan, Ratna Kishore Velamati, Numerical study of effect of pitch angle on performance characteristics of a HAWT, Engineering Science and Technology, an International Journal, Volume 19, Issue 1, 2016, Pages 632-64

Wu, J.-T., Chen, J.-H., Hsin, C.-Y., and Chiu, F.-C. (2018). A computational study on system dynamics of an ocean current turbine. Journal of Hydrodynamics, 30(3), 395-402.

G. Tabor, A. D. Gosman and R. I. Issa, Numerical simulation of the flow in a mixing vessel stirred by a Rushton Turbine, IChemE Symposium Series 140:25-34, 1996

Wu Hsing-nan, Long-jeng Chen, Ming-huei Yu, Wen-yi Li and Bang-fuh Chen, (2012) "On design and performance prediction of the horizontal-axis water turbine", Ocean Engineering (50), 23-30.

Po-Hung Yeh, Shang-Yu Tsai, Wei-Ren Chen, Shih-Meng Hsu, Bang-Fuh Chen, (2021), A platform for Kuroshio Energy Harvesters Ocean Engineering 223 (2021) 108693.

M. Zadravec, S. Basic, M. Hribersek, The influence of rotating domain size in a rotating frame of reference approach for simulation of rotating impeller in a mixing vessel, Journal of Engineering Science and Technology, Vol. 2, No. 2 (2007) 126 - 138 